\title{
CONTROL OF REPRODUCTION IN FEMALE COCKROACHES WITH SPECIAL REFERENCE TO NAUPHOETA CINEREA. \\ II. GESTATION AND POSTPARTURITION.
}

\author{
By Louis M. Roth \\ Pioneering Research Division \\ U.S. Army Natick Laboratories, Natick, Massachusetts
}

In Part I (Roth, 1964) of this paper I presented the results of a study on the reproductive behavior during the first preoviposition period of 4 species of cockroaches that incubate their eggs internally. Nauphoeta cinerea (Olivier) was the principal species used, but some experiments were conducted on Leucophaea maderae (Fabricius), Pycnoscelus surinamensis (Linnaeus), and Diploptera punctata (Eschscholtz).

In both $N$. cinerea and $L$. maderae receptivity can be correlated with the beginning of yolk deposition in the oöcytes. Yolk deposition in cockroaches is dependent upon corpus allatum hormone (Scharrer, 1946; Engelmann, 1957a, 1959; Roth and Stay, 1961, 1962b). Since allatectomized females mate (Roth and Barth, I964), receptivity is determined by some event, presumably in the brain, which occurs at about the same time as onset of activity of the corpora allata; it was suggested that the neurosecretory system is involved in acceptance of the male by the female.

Females of $N$. cinerea become sexually receptive and mate at an average age of 4 days; females that are starved from emergence mate at the same age as fed individuals. Females of L. maderae also undergo a precopulatory period before they become receptive, and mate at an average age of 9 days. In this species more than 50\% of the females that are starved from emergence do not mate (Roth, 1964). Thus, in virgin females starvation affects receptivity in $L$. maderae but not in $N$. cinerea (Roth, 1964).

Once a virgin $N$. cinerea mates, she becomes unreceptive and will not mate again during the first preoviposition period. Mechanical stimulation caused by the firm insertion of the spermatophore in the bursa copulatrix inhibits the female's sexual feeding response on the male's tergum (Roth, 1962, 1964). Whereas insertion of the spermatophore renders the female unreceptive it increases the activity of the corpora allata resulting in rapid development of the oöcytes. There appears to be a synergistic action of nutrition and mating 
stimuli in controlling the rate of oöcyte development because both stimuli are usually required in $N$. cinerea and $L$. maderae for activating the corpora allata to their fullest extent so that the oöcytes mature at their maximum rate (Roth, 1964).

In $N$. cinerea, the growth of the oöcytes remain inhibited during most of the gestation period (Roth and Stay, 1962b). The female remains sexually unreceptive during gestation and will not mate. She may or may not mate again after parturition (Roth, 1962). Obviously, a pregnant female, or one that has given birth, differs physiologically from a virgin female or one that has mated but not yet oviposited. This report concerns the control of, and factors affecting sexual receptivity and oöcyte development during gestation and after parturition.

\section{MATERIALS AND METHODS}

Nauphoeta cinerea was the principal species used, but several experiments were also performed on L. maderae, and the bisexual and parthenogenetic strains of Pycnoscelus surinamensis (Roth and Willis, 1961). The insects were reared and maintained on Purina dog chow or laboratory chow. Methods for testing receptivity, determining corpus allatum activity, operating on females, and laboratory conditions are given in Roth (1964).

To determine the effect of uterine pressure on oöcyte development, artificial oöthecae made of glass rods or beads were inserted in the brood sacs after the oöthecae were removed manually. To reduce the size of the oötheca, various numbers of eggs were removed from the females of $N$. cinerea as oöthecae were being formed (Roth and Hahn, 1964). Other techniques are described in their appropriate sections in the text. Numbers following \pm are standard errors of mean values. Unless otherwise indicated, parturition refers only to birth of the first litter.

\section{RESULTS AND CONCLUSIONS \\ Mechanism of inhibition of the oöcytes during gestation}

The growth of the oöcytes during gestation in $N$. cinerea is shown in figure I. Gestation may last 35-50 days. After 35 days of pregnancy, the oöcytes in different individuals may vary considerably in length. Many females may have oöcytes that contain large amounts of yolk prior to or at the time of parturitition.

When the oöthecae are removed from pregnant females, the oöcytes mature prematurely, indicating that an inhibitory influence 


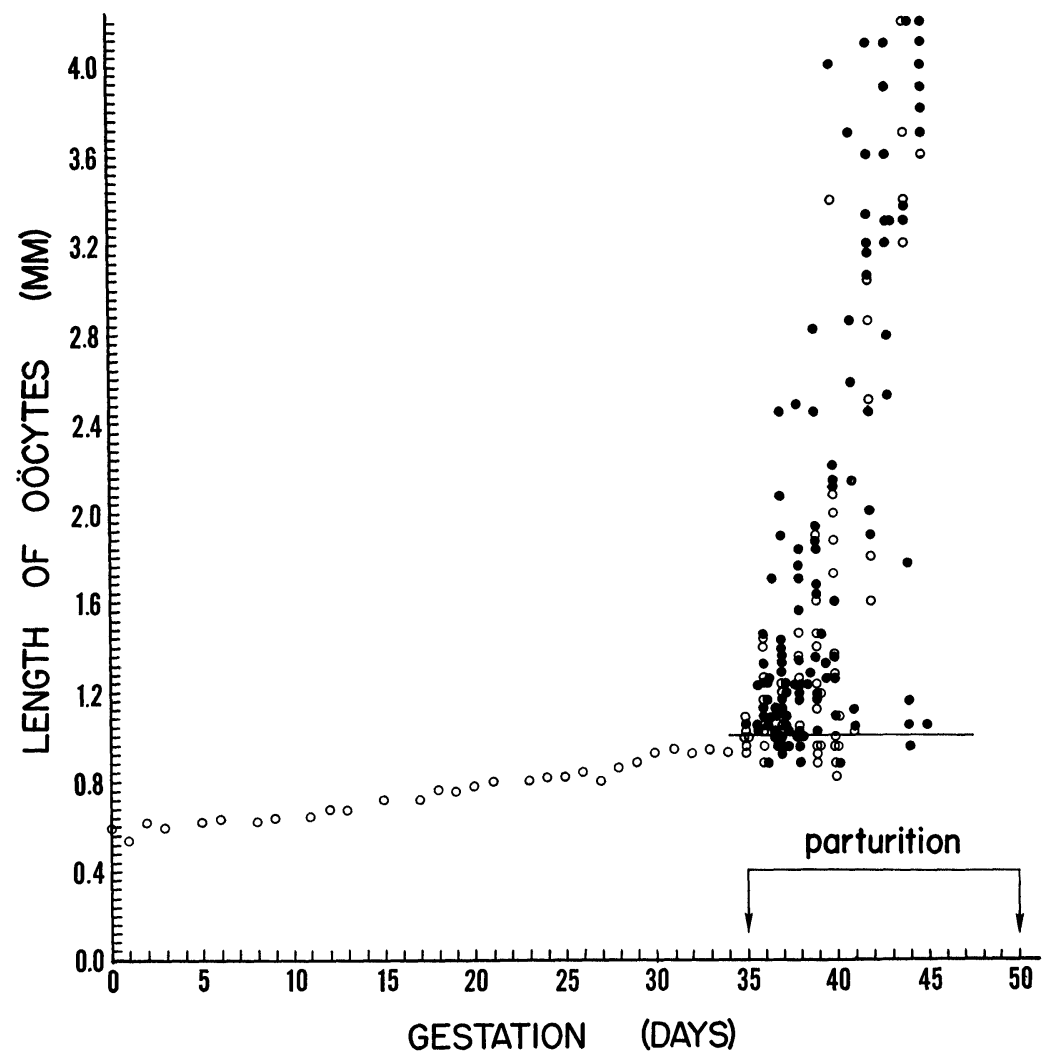

Fig. 1. Oöcyte development during pregnancy in $N$. cinerea. All points from 0-34 days are mean values of $5-9$ individuals $(N=197)$; standard errors are not indicated but were $\pm 0.04 \mathrm{~mm}$. or less for all of these measurements. Each point beyond 35 days of pregnancy represents the oöcytes of one female. Open circles $=$ females were still carrying oöthecae when dissected. Solid circles $=$ females dissected at the time of parturition or within $24 \mathrm{hr}$. after giving birth. The horizontal line is drawn at $1 \mathrm{~mm}$. which is about the minimum size of the oöcytes that contain yolk.

on the corpora allata has been removed. The older the uterine eggs when removed, the less time is required to ovulate again (fig. 2). Roth and Stay (I959, 1961, 1962a, b) concluded that mechanical stimuli resulting from the oötheca in the uterus inhib:t the corpora allata during pregnancy. Engelmann (1964) believes that in $L$. maderae the corpora allata are inhibited by a substance 


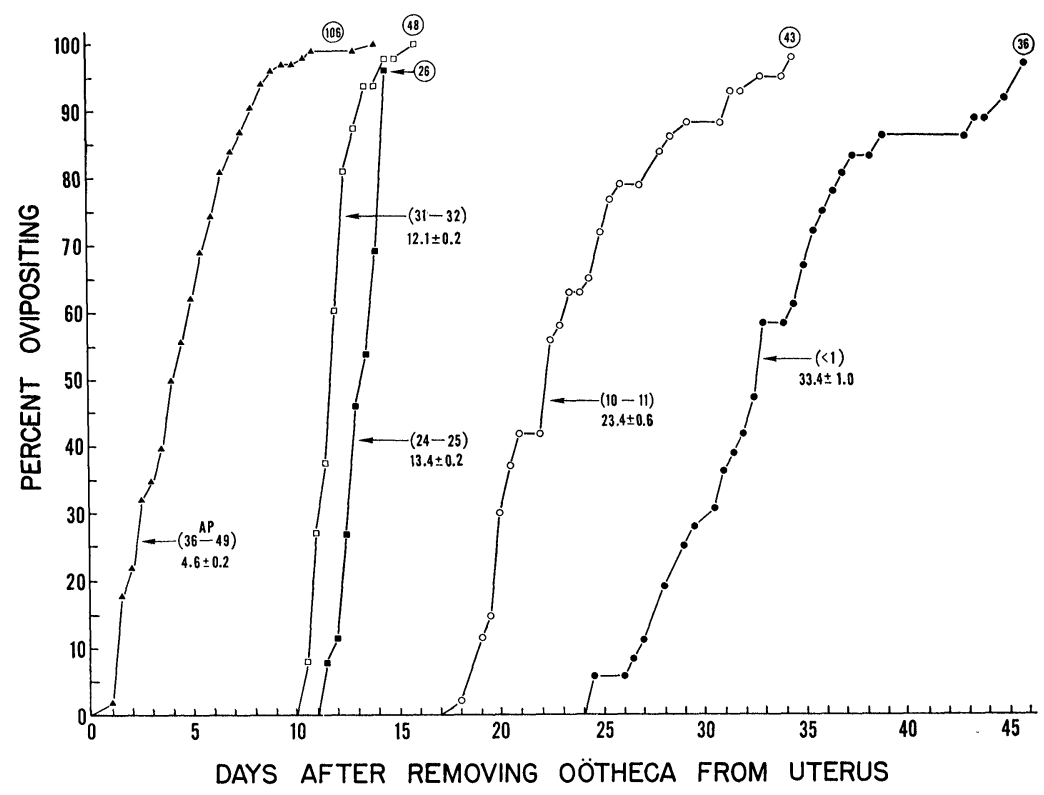

Fig. 2. Relationship between the age of the oötheca at the time it was removed from the uterus of $N$. cinerea and the time required to form a new egg case. Numbers in circles $=$ number of insccts used for each curve. Numbers in parentheses $=$ number of days females were pregnant when their oöthecae were removed. AP $=$ after parturition; 36-49 represents the range (days) of gestation in these females. Numbers under parentheses $=$ mean number of days \pm standard error, to form a new oötheca. The per cent ovipositing is expressed as accumulative data.

released by the egg case or brood sac, acting on neurones in the nerve cord and brain.

To determine if a chemical agent or mechanical stimulation prevents the growth of oöcytes in $N$. cinerea during pregnancy, glass tubes were inserted in the uteri of females after their oöthecae were removed at 3 different periods of gestation. The results (figs. 3,4) show that with glass oöthecae, the oöcytes did not develop as rapidly as they did in females in which no tubes were inserted in the uteri, indicating that the corpora allata were inhibited by the artificial egg cases. When oöthecae were removed about 24 hours after oviposition, females oviposited again on an average of 33 days; when oöthecae were removed IO - I I days after oviposition, the average time taken to oviposit again was 23 days (fig. 2). In both groups of females 


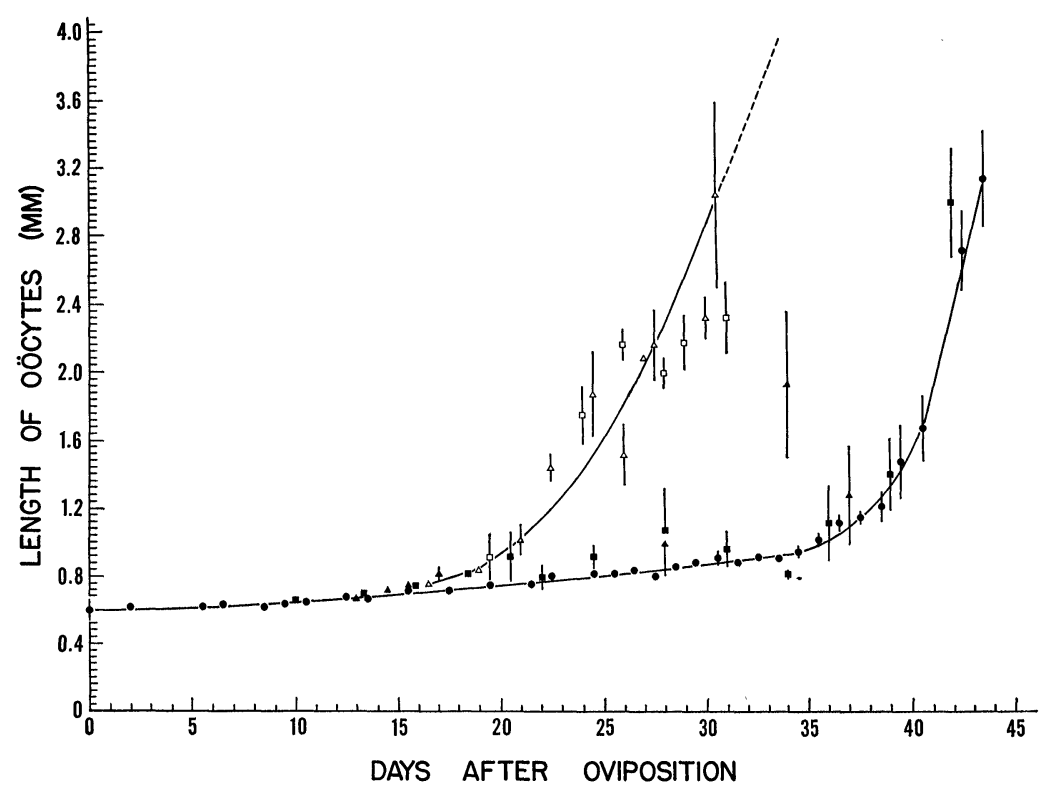

Fig. 3. Effect of distention of the uterus on inhibition of the corpora allata during early gestation in $N$. cinerea. Solid circles $=$ Carrying oöthecae (controls). Five to 18 females per point $(\mathrm{N}=276)$. Open squares $=$ oöthecae removed $<24 \mathrm{hr}$. after ovipositing; no glass tube inserted in uteri. Five to 16 females per point $(\mathrm{N}=65)$. Solid squares $=$ Oöthecae removed $<24$ hr. after ovipositing, glass tube $(3-3.5 \mathrm{~mm}$. $\times 10-11 \mathrm{~mm}$. $)$ inserted in uteri. Four to 10 females per point $(\mathrm{N}=99)$. Open triangles $=$ Oöthecae removed 10-11 days after ovipositing; no glass tube inserted in uterus. Three to 12 females per point $(\mathrm{N}=65)$. Solid triangles $=$ Oöthecae removed 10-11 days after ovipositing; glass tube $(3-3.5 \mathrm{~mm}$. $\times 10-11$ $\mathrm{mm}$.) inserted in uteri. Four to 10 females per point $(\mathrm{N}=42)$. Vertical bars are one standard error but only one-half the error is indicated where they overlapped; no bars indicate standard errors of $\pm 0.02 \mathrm{~mm}$. or less. A single curve is drawn through open triangles and open squares (see text for explanation).

the average time to oviposit again after the initial oviposition was about 33 days and for this reason in figure 3 ( $\Delta$ and $\square$ ), a single curve is drawn through the points for females whose oöthecae were removed about 24 hours, and IO - I I days after oviposition. Eventually, inhibition of the corpora allata ceased in females with glass tubes in the uteri and the oöcytes developed. This also occurs in normal pregnant females in late gestation (fig. I). Inhibition may 


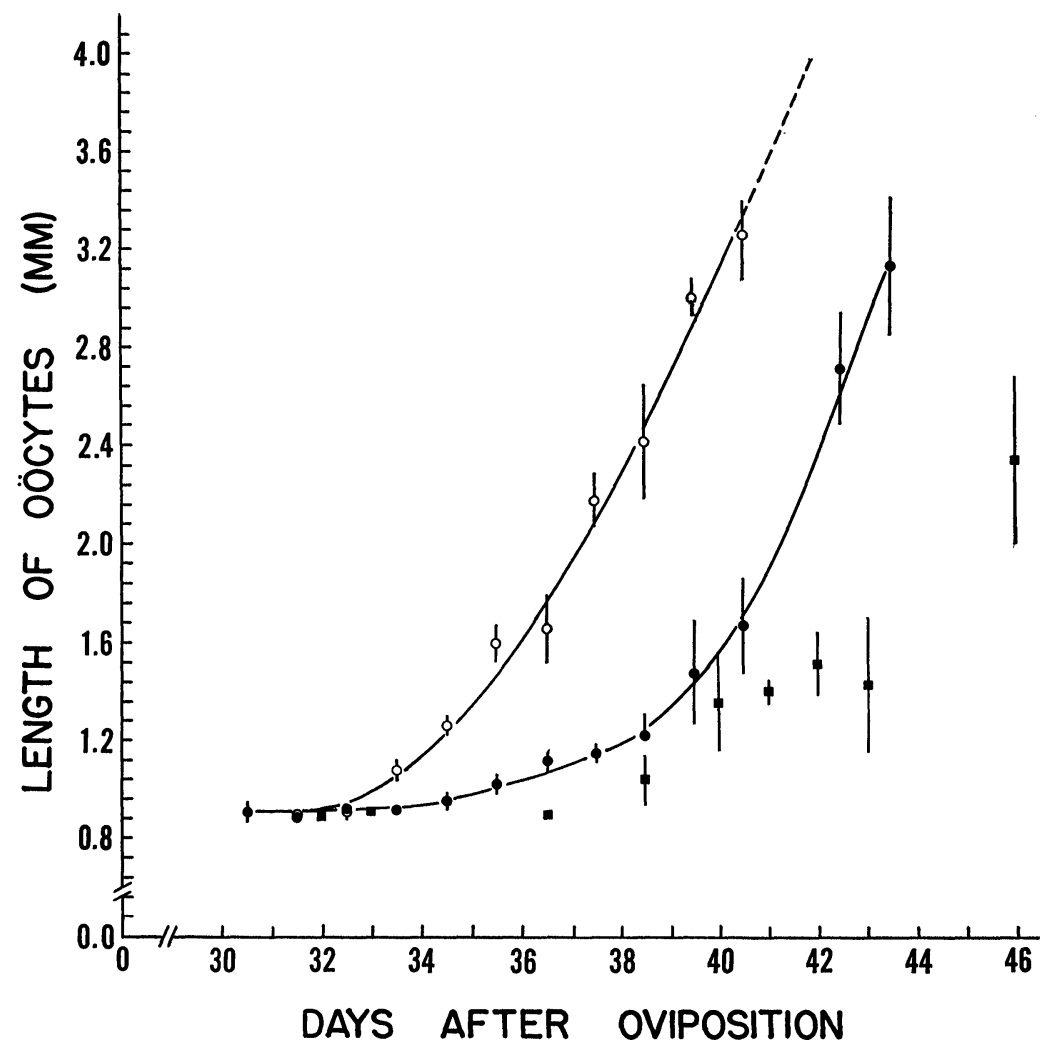

Fig. 4. Effect of distention of the uterus on inhibition of the corpora allota during late gestation in $N$. cinerea. Solid circles = Carrying oöthecae (controls). Ten to 18 females $(\mathrm{N}=143)$ used for each point. Open circles $=$ Oöthecae removed 30-31 days after oviposition; no tube inserted in uteri. Ten females $(\mathrm{N}=100)$ used for each point. The average time required to oviposit again, when the oöthecae were removed at $31-32$ days of pregnancy, was 12 days (fig. 2) or 43-44 days after the initial oviposit:on. Solid squares $=$ Oöthecae removed from females $30-31$ days after oviposition and glass tubes $(4.1-4.3 \mathrm{~mm}$. $\times 10-11 \mathrm{~mm}$.) inserted in the uteri. Five to 16 females $(\mathrm{N}=92)$ used for each point. Vertical bars are one standard error but only one-half the error is indicated where they overlapped; no bars indicate standard errors of $\pm 0.02 \mathrm{~mm}$. or less.

cease earlier in some females with glass inserts than in females carrying oöthecae (fig. 3).

The effect of different degrees of uterine stretching, using glass rods, and glass beads of 3 different diameters, was investigated in 
2 strains of $P$. surinamensis. The artificial oöthecae were inserted into the uteri of females after their oöthecae were removed $<24 \mathrm{hr}$. after ovipositing. The results are shown in figure 5 and table $\mathrm{I}$. The oöcytes of some females with bead inserts developed as rapidly as in females without beads. In the bisexual strain, the largest bead, and consequently the greatest uterine streching, was more effective than the two smaller beads in inhibiting the corpora allata. In the parthenogenetic strain, $4.0 \mathrm{~mm}$. beads were about as effective as $4.5 \mathrm{~mm}$. beads (table $\mathrm{I}$ ). The bead experiments were conducted for a maximum of 56 days in the parthenogenetic strain and for 37 days in the bisexual strain. In the glass rod experiments, females were sacrificed from 27-IOO days after the rods were inserted in the uteri. Inhibition was virtually complete in all females (table $\mathrm{I}$ ), their oöcytes ranging in size from $0.58-0.88 \mathrm{~mm}$. long $(\overline{\mathbf{x}}=0.74 \pm 0.0 \mathrm{Imm}$.). Of 68 bisexual strain females that had rods inserted in their uteri, only 3 females had well-developed oöcytes when examined on the I 7 th, 25th, and 36th days. The other 65 females had oöcytes that were virtually completely undeveloped when examined 24-7I days after the rods were inserted; their oöcytes ranged from $0.54-0.95$ $\mathrm{mm}$. and averaged $0.7 \mathrm{I} \pm 0.0 \mathrm{Im}$. in length.

It was of interest to determine if reduction in size of the oötheca would influence the size of the ovarian oöcytes at parturition. There are an average of 33 eggs in the oötheca of $N$. cinerea (Willis et al., 1958). The results of reducing the number of eggs in the oötheca are shown in figure 6 . The oöcytes of females that had carried small oöthecae were not larger than the oöcytes of the control females.

Fig. 5. Effect of distention of the uterus with glass beads on inhibition of the corpora allata during gestation in two strains of $P$. surinamensis. Solid circles $=$ Carrying oöthecae (controls). Each point represents one female or is an average value of $2-5$ females. Bisexual $-\mathrm{N}=107$; barthenogenetic $-\mathrm{N}=75$. Open circles $=$ Oöthecae removed $<24 \mathrm{hr}$. after ovipositing; no glass beads inserted in uteri. Bisexual - 9-16 females per point $(\mathrm{N}=189)$; parthenogenetic $-4-14$ females per point $(\mathrm{N}=96)$. The 3 remaining symbols were females whose oöthecae were removed $<24$ hr. after oviposition and glass beads of the following approximate diameters were inserted in the uteri; open squares $=3.5 \mathrm{~mm}$. Bisexual $-7-11$ females per point $(\mathrm{N}=86)$; parthenogenetic $-5-8$ females per point $(\mathrm{N}=36)$. Open triangles $=4.0 \mathrm{~mm}$. Bisexual $-8-15$ females per point $(\mathrm{N}=65)$; parthenogenetic $-3-10$ females per point $(\mathrm{N}=48)$; solid squares $=4.5$ mm. Bisexual - 10-13 females per point $(\mathrm{N}=44)$; parthenogenetic 6 -9 females per point $(\mathrm{N}=49)$. Curves are drawn through solid and open circles only. For the points indicating females with bead inserts, vertical lines are one standard error of mean values; no vertical lines indicate standard errors of $\pm 0.02 \mathrm{~mm}$. or less. 


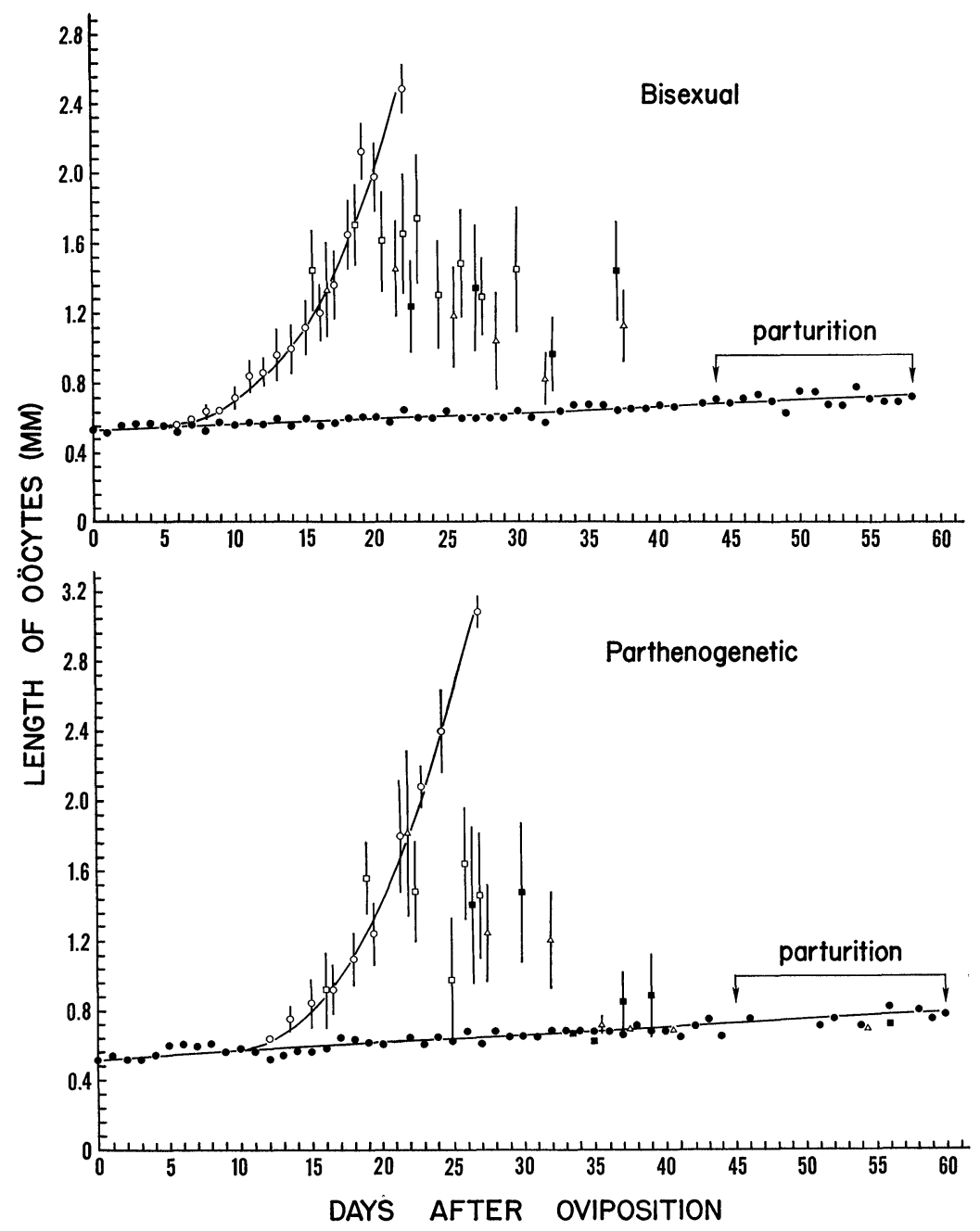

If small oöthecae, and, consequently, less stretching of the uterus (principally lengthwise), were less effective than normal-sized egg cases in inhibiting the corpora allata, one would expect the oöcytes to be larger at parturition. Since the small oöthecae are considerably reduced in length, the results suggest that in $N$. cinerea: I ) transverse rather than longitudinal stretching of the uterus, and 2) the gradual increase in size of the uterine eggs, even in oöthecae with 


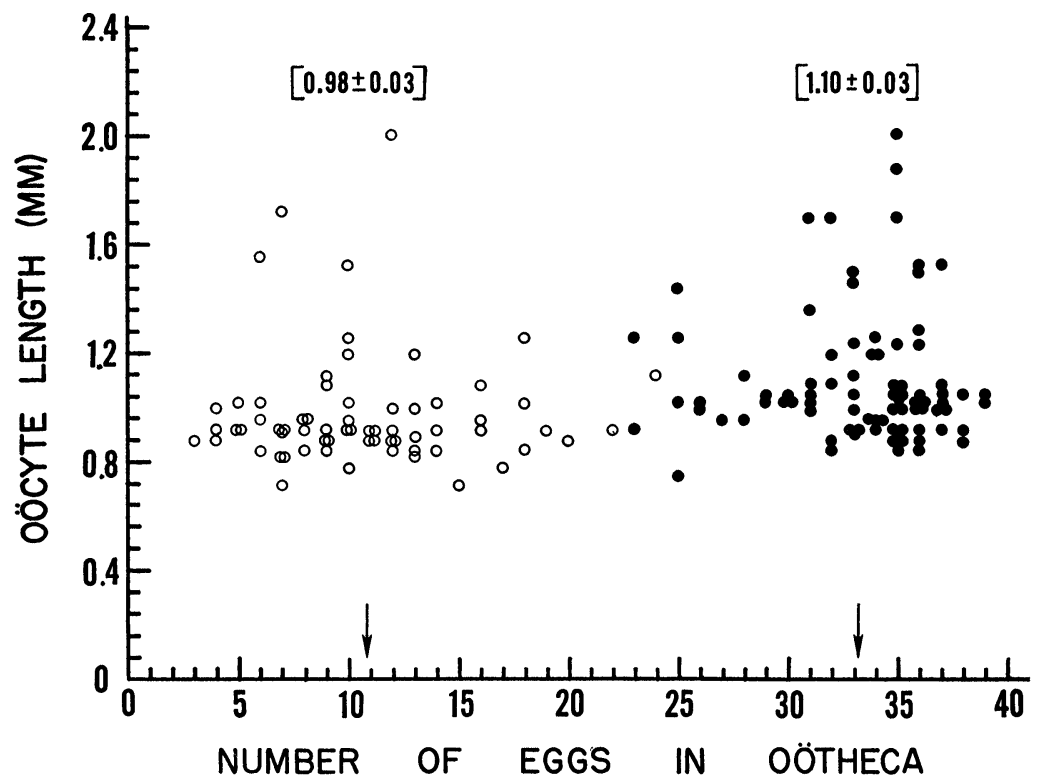

Fig. 6. Effect of reducing the number of eggs in the oötheca on the size of oöcytes at parturition in $N$. cinerea. Open circles $=$ number of eggs in oöthecae reduced manually $(\mathrm{N}=66)$. Solid circles $=$ number of eggs in oöthecae not reduced manually (controls; $N=84$ ). Each circle represents one female. Arrows indicate the average number of eggs in the oöthecae for the 2 groups of females. Numbers in brackets are the mean lengths \pm standard errors of the oöcytes for both groups. Oöcytes were measured $<24 \mathrm{hr}$. after parturition. Gestation period for the females whose oöthecae were artificially reduced in size averaged 60 days and for the control group 58 days. (Room temperature.)

very few eggs, are important in inhibiting the corpora allata during pregnancy.

\section{Mechanism of inhibition of receptivity during gestation}

Pregnant females of $N$. cinerea are unreceptive and do not respond to the courting male (Roth, 1962). Eight pregnant females had their ventral nerve cords transected $<24 \mathrm{hr}$. after ovipositing. They were exposed to males for $\mathrm{I}-2 \mathrm{hr}$. trials daily to determine if they would mate. Six females mated in 2-8 days after cord transection; one mated 18 days after transection. The spermatophores were attached to the surface of the oötheca, usually in the vestibule, because 


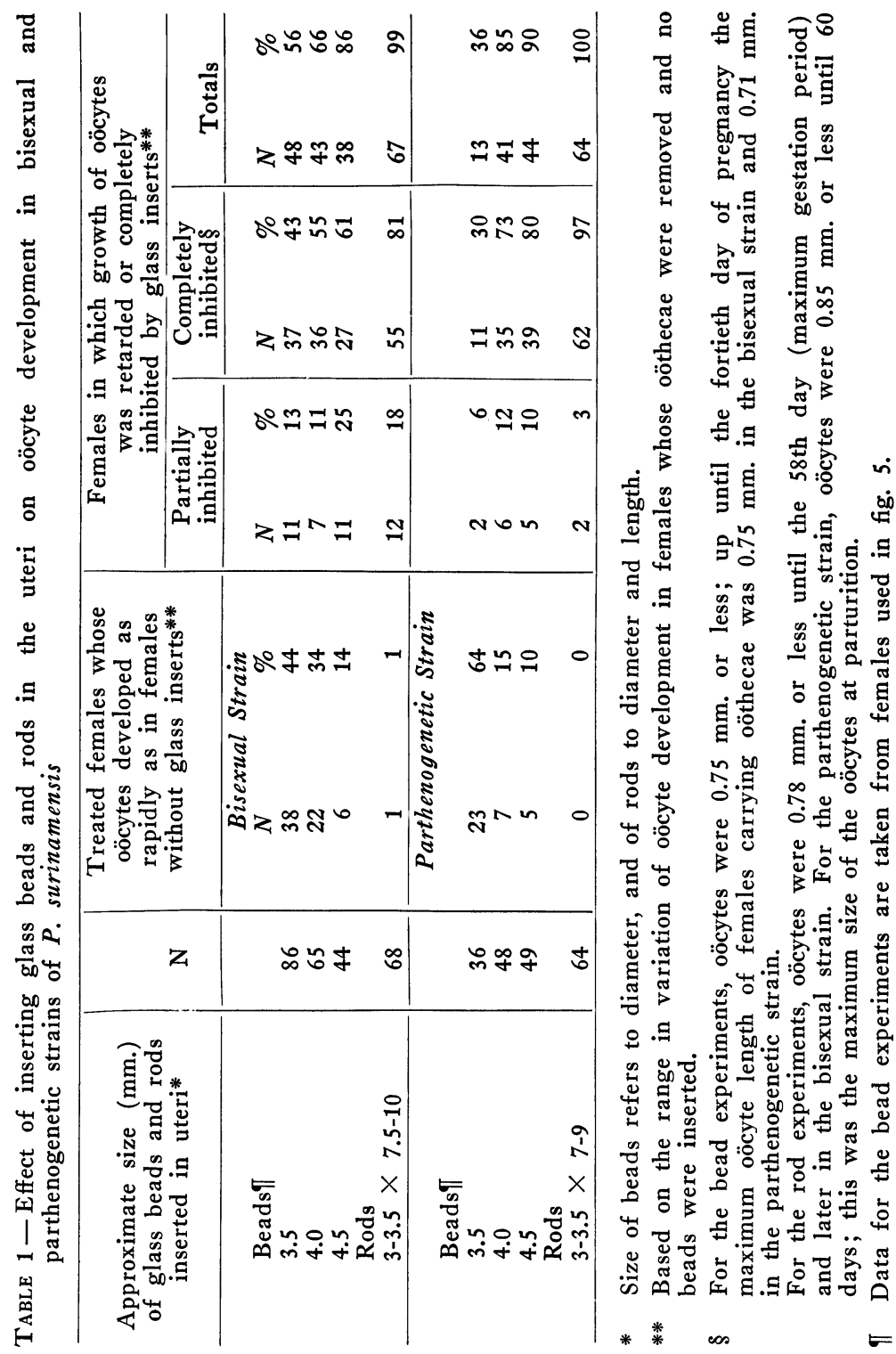




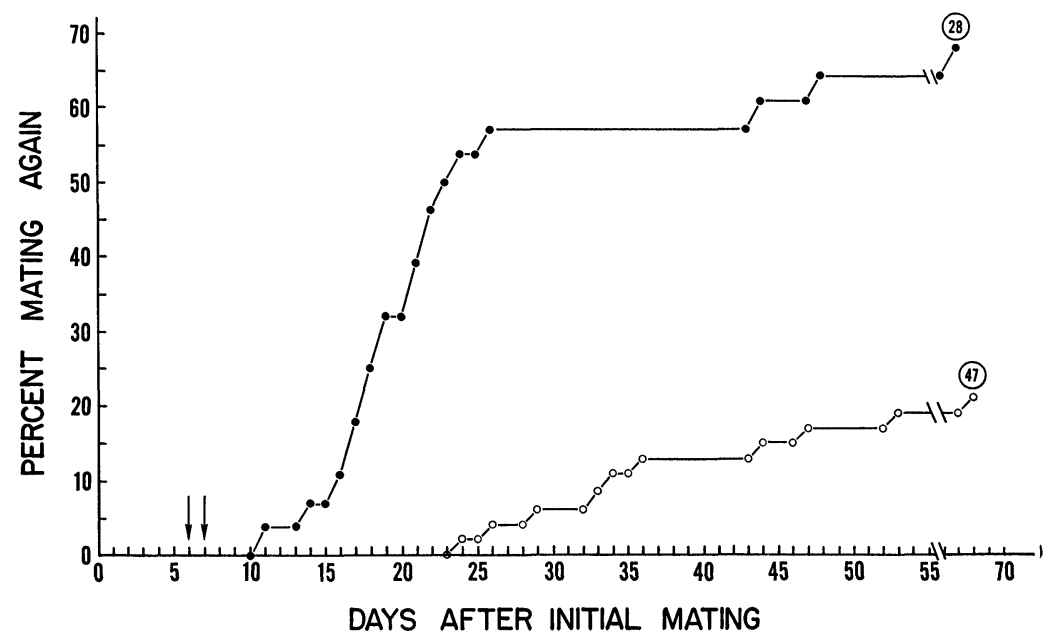

Fig. 7. Effect of ovariectomy on subsequent return of receptivity of females of $N$. cinerea. Open circles $=$ ovariectomized only. Solid circles $=$ ovariectomized; glass tube inserted in uterus on the sixth or seventh days (arrows) after mating; tubes then removed 3-10 days after being inserted and the females kept with males until they mated. Numbers in circles indicate the number of females used. Per cent mating is expressed as accumulative data.

the egg case blocked the bursa copulatrix. Thus in mated females, as in virgin females that oviposit (Roth, I964), the mechanical presence of the oötheca inhibits receptivity.

Ovariectomized (ovaries removed in last nymphal stage) females of $N$. cinerea mate within 3-6 days after emergence. When kept with males continuously only about $20 \%$ of ovariectomized females mated again and this occurred over about a 2-month period (fig. 7). Thus, either the lack of ovaries or oötheca in some way prevented return of receptivity. Sixteen pregnant females had their oöthecae and ovaries removed I2-13 days after oviposition; eleven (69\%) mated 7-I7 days after the operation, showing that the presence of the ovaries themselves were not needed for the return of receptivity. $N$. cinerea nymphs were ovariectomized and the resulting adults were mated 3-6 days after emergence. After the spermatophores were dropped ( $6-7$ days after copulation), glass tubes (about 4.3 $\mathrm{mm}$. $\times$ IO $\mathrm{mm}$.) were inserted into the uteri; the posterior ends of the tubes extended beyond the abdomen and were cemented to the last abdominal segment to prevent their being extruded. After re- 


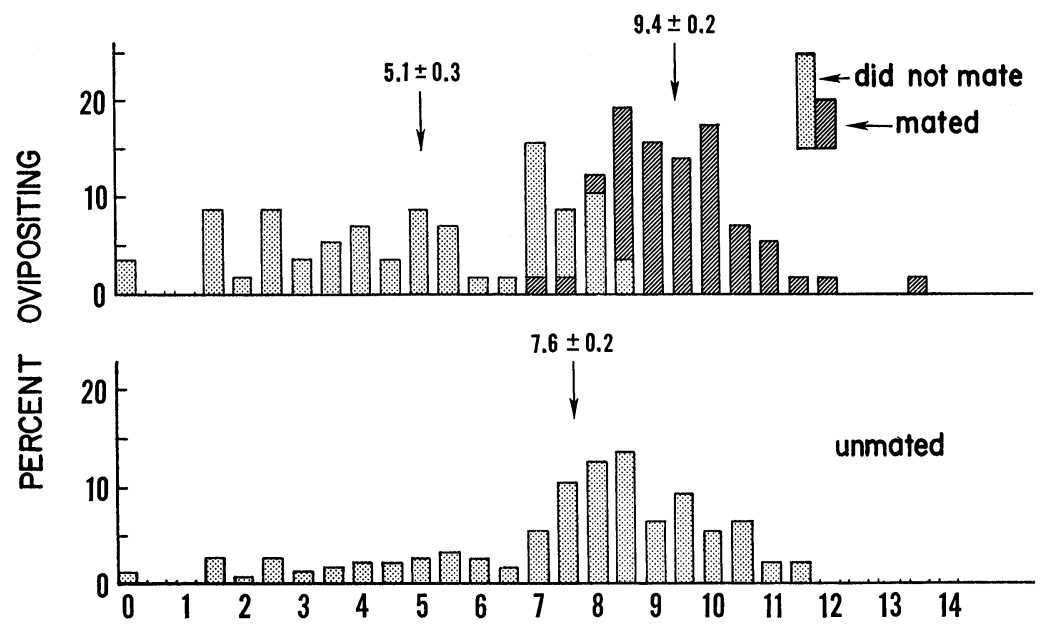

Fig. 8. Relationship between receptivity and subsequent oviposition, and the effect of mating following parturition on oviposition in $N$. cinerea. Top: Females that did or did not mate when exposed to males from time of, or $<24 \mathrm{hr}$. after, parturition. ( $\mathrm{N}=57$ for each group). Bottom: Females that were not mated after parturition. $(\mathrm{N}=181)$. All females had mated previously only once, as virgins, prior to the first oviposition. Gestation period for all females ranged from 36-48 days. Arrows and numbers indicate the mean days \pm standard errors to oviposit for each of the three groups.

maining in the uteri for 3 - Io days, the tubes were removed and the females were placed with males continuously. About $70 \%$ of the females treated in this manner eventually mated and these generally became receptive earlier than ovariectomized females that had not had artificial oöthecae inserted (fig. 7). These results suggest that the prerequisites for the return of receptivity in the normal period of time in mated females are I) the presence of an oötheca (uterine stretching) for at least a short time and then 2) the absence of the oötheca (removal of stretch stimuli).

Receptivity of females after parturition, and the effect of mating on oöcyte deevlopment

Females of $N$. cinerea may or may not mate again after they give birth (Roth, 1962). If not mated after parturition, females averaged about 8 days to oviposit (fig. 8 , bottom). The time required for 
oviposition by females which did or did not mate when exposed to males after parturition is shown in figure 8 (top). Females which mated oviposited later than those that did not mate, indicating that the females which were receptive afer parturition had comparatively smaller oöcytes (see below) and therefore took longer to oviposit than the unmated females. This apparent lack of stimulation of mating differs from that produced by mating during the first preoviposition period where firm insertion of the spermatophore results in an increase in the rate of development of the oöcytes (Roth, 1964).

In $L$. maderae, mating after parturition also does not accelerate oöcyte maturation (Engelmann, I960a). Leucophaea maderae differs from $N$. cinerea in that the time taken to oviposit after parturition in females that do or do not mate is essentially the same; I $4.5 \pm 0.5$ days and $15.4 \pm 0.3$ for mated and unmated females respectively (table 9), whereas $N$. cinerea females that do not mate oviposit sooner than mated females. The difference between these species apparently is due to the fact that in L. maderae the corpora allata are inhibited during the entire gestation period and the oöcytes of females at parturition are more or less the same size and do not contain yolk (see fig. 7 in Roth and Stay, 1962b); in N. cinerea the oöcytes at parturition may vary considerably in size (figs. I, 6).

At high $\left(26^{\circ}-28^{\circ} \mathrm{C}\right.$. $)$, fairly constant insectary temperatures, the number of $N$. cinerea which have yolk in the oöcytes at or prior to parturition was greater than females maintained at usually lower, markedly fluctuating, room temperatures (fig. 9, bottom). Females which become receptive after parturition generally mate within 24 hr. Figure 9 (top) shows the lengths of the oöcytes about $24 \mathrm{hr}$. after parturition of females that did and did not mate when they had access to males. The females with comparatively small oöcytes

TABLE 2-Relationship between length of gestation period and receptivity following parturition in $N$. cinerea

\begin{tabular}{c|cc}
\hline Gestation period (days) & Number used and percent mating* \\
\cline { 1 - 3 } $35-36.5$ & $N$ & $\%$ \\
$37-38.5$ & 28 & 79 \\
$39-40.5$ & 69 & 75 \\
$41-42.5$ & 31 & 36 \\
$43-44.5$ & 28 & 11 \\
$45-46.5$ & 36 & 19 \\
$47-50$ & 16 & 25 \\
\hline
\end{tabular}

* Females kept with males until they mated or oviposited. 
TABLE 3-Effect of starvation and delayed exposure to males on receptivity of $L$. maderae following parturition

\begin{tabular}{|c|c|c|c|}
\hline Treatment after parturition $\mathbb{T}$ & & $\begin{array}{l}\text { used } \\
\text { rcent } \\
\text { ag }\end{array}$ & $\begin{array}{c}\text { Days to mate } \\
\text { after exposure to } \\
\text { males } \\
\text { (Mean } \pm \text { S. E.) }\end{array}$ \\
\hline With food and males & & $\begin{array}{l}\% \\
92\end{array}$ & $1.2 \pm 0.2$ \\
\hline $\begin{array}{l}\text { With food but isolated from } \\
\text { males for } 7-8 \text { days, then starved } \\
\text { and exposed to males }\end{array}$ & 26 & 23 & * \\
\hline $\begin{array}{l}\text { Starved and isolated from males } \\
\text { for } 7-8 \text { days, then with food and } \\
\text { males }\end{array}$ & 24 & $92 * *$ & $1.4 \pm 0.4$ \\
\hline
\end{tabular}

I Food for all groups was lab chow; all groups had been fed during gestation.

* The 6 females that mated did so immediately or within a few hours after being with males; their oöcytes averaged $2.84 \pm 0.35 \mathrm{~mm}$. Fifteen of the 20 females that did not mate oviposited $16.1 \pm 0.4$ days after parturition (the exact time to oviposit of 5 females was not known).

** The oöcytes of the females that mated averaged $1.51 \pm 0.10 \mathrm{~mm}$.

mated, whereas females whose oöcytes were fairly large shortly after parturition tended to be unreceptive. This relationship was true for females which had two litters and had mated once or twice prior to the second parturition. Of 58 females that mated once, prior to the first oviposition, and were then exposed to males after having the second litter, only 9 ( $16 \%$ ) mated again, and their oöcytes measured I.I9 $\pm 0.06 \mathrm{~mm}$. within $24 \mathrm{hr}$. after mating. The mean oviposition time after parturition for the 49 (84\%) females that did not mate was $4 . \mathrm{I} \pm 0.3$ days. Sixty-three females were mated twice (once prior to the first oviposition and once after giving birth to the first litter) and were exposed to males after the second parturition. Thirty-two (5I\%) mated again and the oöcytes of these females were I.I $7 \pm 0.04 \mathrm{~mm}$. long within $24 \mathrm{hr}$. after mating. The 3I $(49 \%)$ females that were unreceptive and did not mate oviposited in $5.6 \pm 0.6$ days, again indicating that their oöcytes were well developed at the time of parturition; females that mate oviposit on an average of 9 days after giving birth (fig. 8, top).

An analysis of the histories of $22 \mathrm{I}$ females that did or did not mate after parturition showed that females with longer gestation periods tended to be sexually unreceptive after they gave birth, whereas those with shorter gestation periods usually mated again 
(table 2). These results again show that after parturition, receptivity can be correlated with relatively small oöcytes because females with longer gestation periods usually have large oöcytes at parturition. It appears that if the oöcytes begin to mature several days before the female gives birth, she will tend to be sexually unreceptive after parturition.

If large oöcytes are an indicator of nonreceptivity following parturition, then females that are receptive at parturition should become unreceptive if isolated from males for several days after giving birth because an additional mating is not necessary for continued development of the oöcytes. The effect on receptivity of isolating females from males for various periods of time after parturition and then placing them with males until they mated or oviposited is shown in figure Io. There was a marked decline in receptivity of females after they had given birth, the longer they were isolated from males. The oöcytes of 30 females that mated after being placed with males 2 - 6 days after parturition averaged only $\mathrm{I} .4 \mathrm{O} \pm 0.06 \mathrm{~mm}$., indicating that in these females the oöcytes were relatively small at parturition. The largest oöcytes of all the females that mated following a delay in exposure to males was $2.21 \mathrm{~mm}$. (she mated 6 days after parturition).

Females of $L$. maderae usually mate within a day or two after parturition and mating after parturition is not required to mature the oöcytes. As in N. cinerea, delayed exposure to males also results in a loss of receptivity in fed females (table 3 ).

\section{Return of receptivity of females after removing the oöthecae from the uteri}

Roth (1962) found that the elapsed time for the return of receptivity following removal of the oöthecae was shorter when the egg case was removed late rather than early in gestation; in that experiment the actual ages of the oöthecae when removed from the uteri were unknown. The return of receptivity in females which had their oöthecae removed at several known periods following oviposition is shown in table 4 and figures II and 12 (done under different temperature conditions). More than $50 \%$ of the control females became receptive within a few hours after giving birth (fig. II, AP). The time required for the return of receptivity in the experimental animals varied and depended on how long the females had been pregnant when their oöthecae were removed. The younger the oöthecae when removed, the longer it took for the return of 

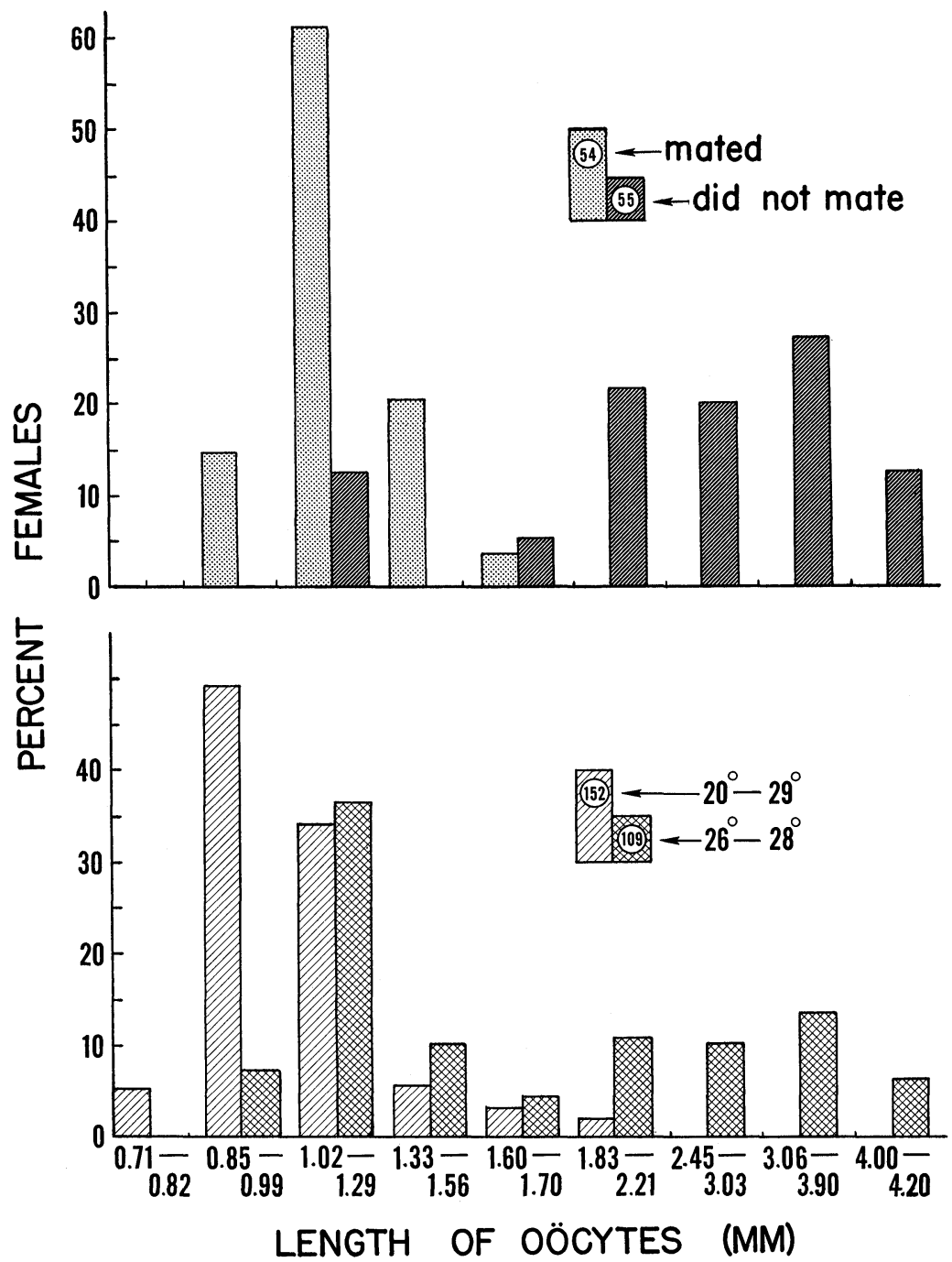

Fig. 9. Relationship between receptivity and size of oöcytes following parturition in $N$. cinerea. Top: Females exposed to males from time of parturition and given $<24 \mathrm{hr}$. to mate. Oöcytes measured within $24 \mathrm{hr}$. after parturition $\left(27 \pm 1^{\circ}\right.$ C. $)$. Bottom: Oöcytes measured at the time of parturition or $<24 \mathrm{hr}$. after the females had given birth. Females maintained during gestation at 2 different room conditions. (Numbers in circles in top and bottom histograms indicate the numbers of insects used for each group). 


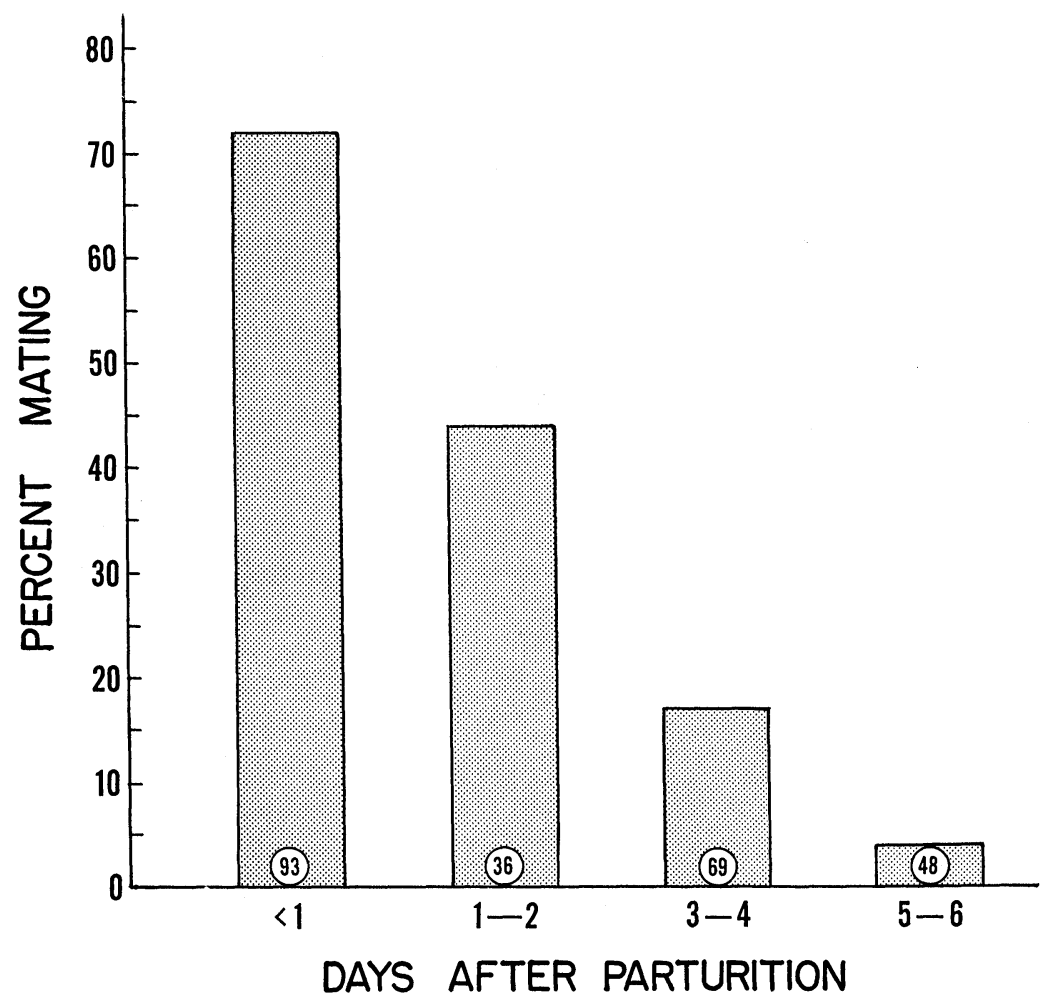

Fig. 10. Effect of delayed exposure to males on receptivity of females following parturition in $N$. cinerea. The axis of abscissas indicates the days after parturition the females were placed with males. Numbers in circles indicate the numbers of females used. Gestation period 35-50 days. Females fed during gestation and after parturition.

receptivity. The results were similar whether females which had their oöthecae removed I- 2 days after ovulation were exposed to males for I hr. daily, or were exposed to males continuously (fig. II, cf. $\square$ and $\Delta$ ). Note the similarity between figures 2 and 12 (both done under similar conditions). The same relationship holds for the return of receptivity as for the time taken to oviposit following removal of the oöthecae at various periods of pregnancy. Virgin females differ from mated individuals in that receptivity returns sooner when the oötheca is removed from the uterus (figs. II, I2; table 4). 


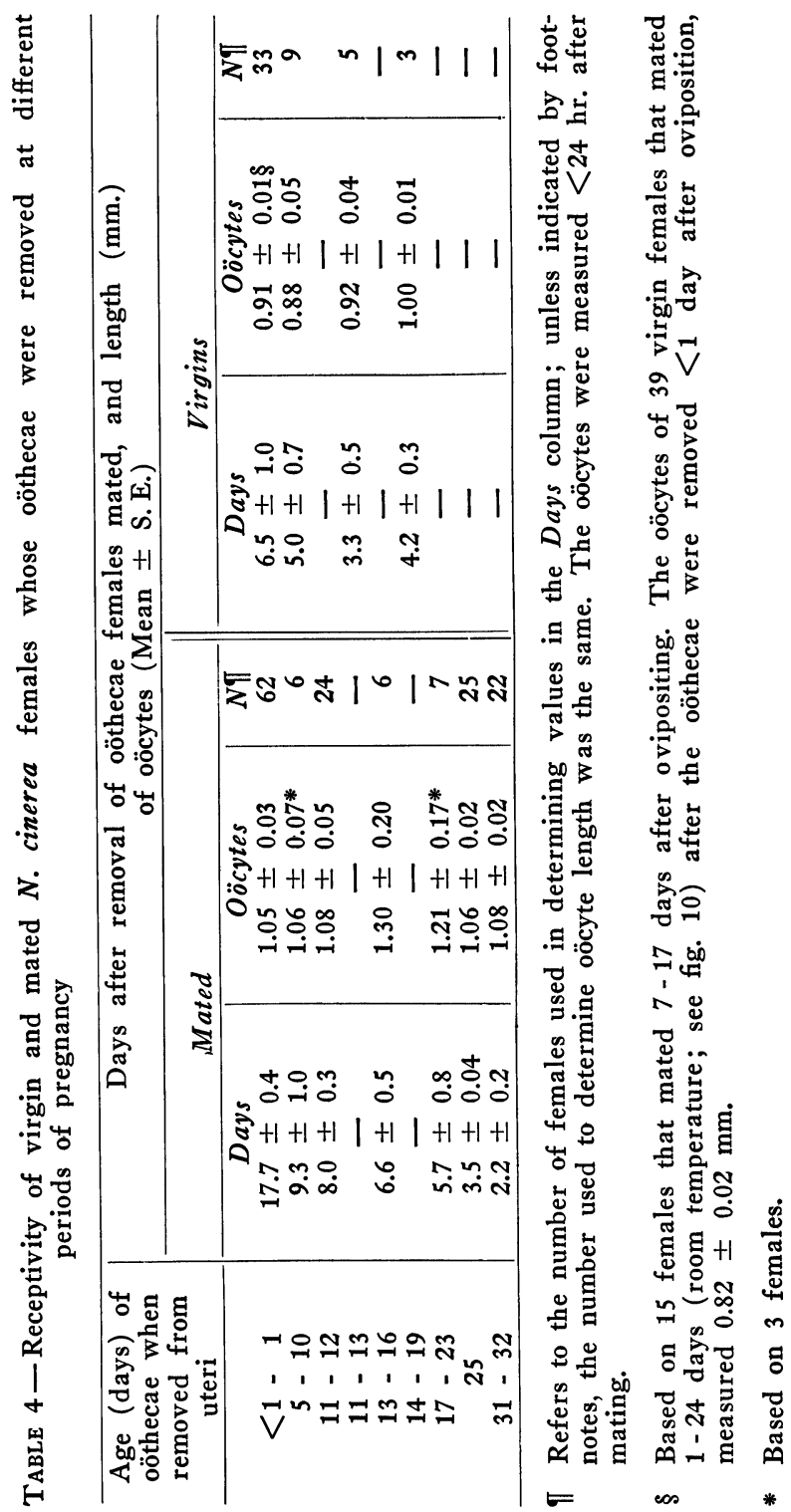


Histograms showing the frequency distributions of the lengths of the oöcytes at the time of mating of the females used in figure II are given in figure I3. Except for females whose oöthecae were removed I- 2 days after oviposition, the greatest percentage of females mated when their oöcytes were $0.99-1.09 \mathrm{~mm}$. long and contained yolk. The basal oöcytes of females whose oöthecae were removed I - 2 days after oviposition are about $0.5 \mathrm{I} \mathrm{mm}$. long and smaller than the oöcytes of females whose oöthecae are removed at 2 I - 26 days or 5 I - 54 days after ovulation, or at parturition. There is an increase in the length of the oöcytes during gestation, even though the corpora allata are inactive during most of the gestation period as indicated by absence of yolk in the oöcytes. When the oötheca is removed just after ovulation, a certain amount of time elapses before the oöcytes attain the length of those of females whose oöthecae were removed near the middle or about the end of the gestation period. Many females that mated after their oöthecae were removed I - 2 days after oviposition, had oöcytes that did not contain yolk; but their colleterial glands usually contained some secretion. However, not all of the colleterial gland secretion is used during the first oviposition so that its presence in the gland after parturition cannot be used as an indicator of corpus allatum activity.

\section{Effect of mating stimuli on return of receptivity}

Females were mated to castrated males. After oviposition their oöthecae were removed at different periods of gestation, and the females were placed with males and checked daily for spermatophores. The return of receptivity (table 5) of these females that lacked sperm in the spermathecae was similar to that found in normally mated females (cf. table 4); the longer the oöthecae had been in the uterus when it was removed, the quicker the females regained receptivity. T'en females (room temperature) were allowed to mate to completion and had their spermatophores removed $\mathrm{I}-2 \mathrm{~min}$. after mating so that no sperm entered the spermathecae (Roth, 1964). After ovipositing (oöthecae were aborted and never had been in the uteri, or were removed $<24 \mathrm{hr}$. after oviposition) they were exposed to males $\left(2 \sigma^{\pi} \sigma^{\pi}\right.$ : I우) for I hr. daily to determine when receptivity would return. Six of the females mated in $16-28$ days $(\overline{\mathrm{x}}=2 \mathrm{1.2} \pm \mathrm{I} .9)$ and their oöcytes averaged $0.99 \pm 0.04$ $\mathrm{mm}$. long. The return of receptivity in these females was similar to that of normally mated females rather than virgin females whose oöthecae were removed (cf. table 4 ). These experiments show that 


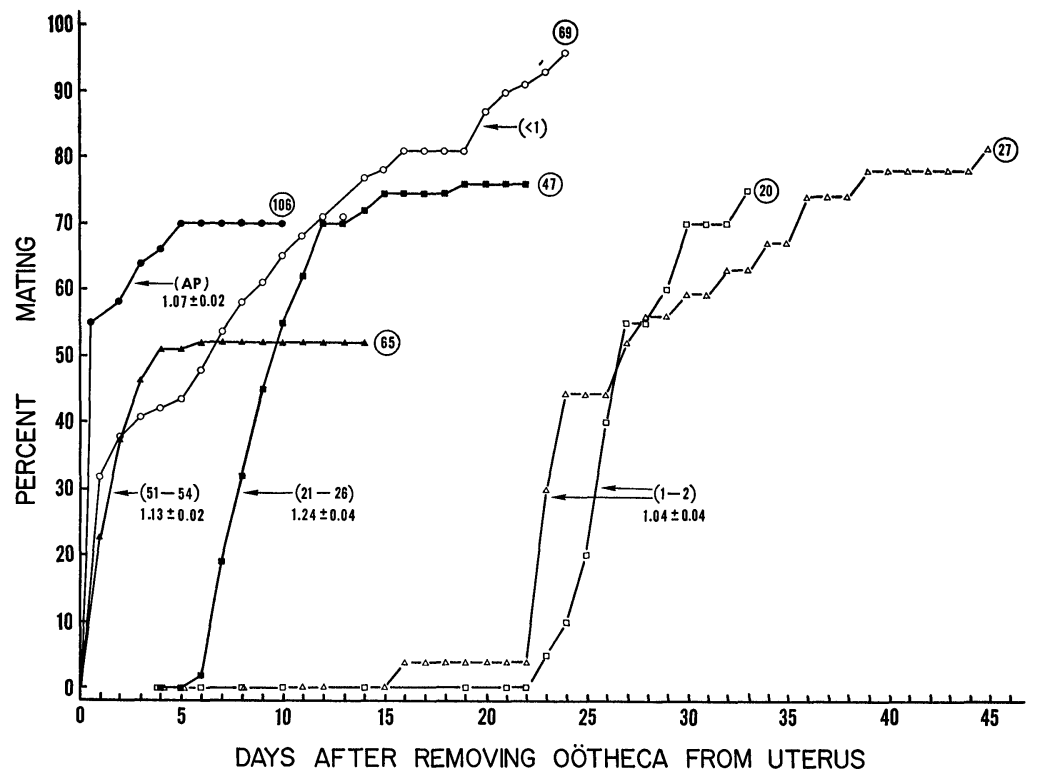

Fig. 11. Relationship between age of oötheca when removed from the uterus and recovery of receptivity in $N$. cinerea. Numbers in circles $=$ numbers of insects used. Numbers in parentheses $=$ number of days females were pregnant when their oöthecae were removed from the uteri. Numbers under parentheses $=$ mean length $(\mathrm{mm}$. $) \pm$ standard errors of the oöcytes, measured at the time of mating (except for females represented by open squares; the oöcytes of these females were measured $<24 \mathrm{hr}$. after mating). $(\mathrm{AP})=$ females that gave birth normally; fifty-five per cent of the females mated $<24 \mathrm{hr}$. after parturition and these are plotted at 0.5 day. The females of this group that failed to mate oviposited 6-10 days after parturition. Open circles $=$ virgin females; all other groups had mated prior to ovipositing. Open squares $=$ each of the females in this group were confined with 2 males continuously until they mated; females examined daily for spermatophores. The females in all other groups were tested for receptivity once a day for one $\mathrm{hr} .(2 \hat{\delta} \hat{O}: 1$ 우 $)$ and were removed when they mated. The per cent mating is expressed as accumulative data. (Room temperature.)

I) prolonged loss of receptivity during gestation can be induced by mating stimuli, i.e., the firm insertion of the spermatophore in the bursa copulatrix, and 2) the absence of sperm in the spermathecae does not influence the return of receptivity after the first oviposition.

Males produce small spermatophores if they mate more than once with brief intervals between matings (Roth, I964) and it is probable 


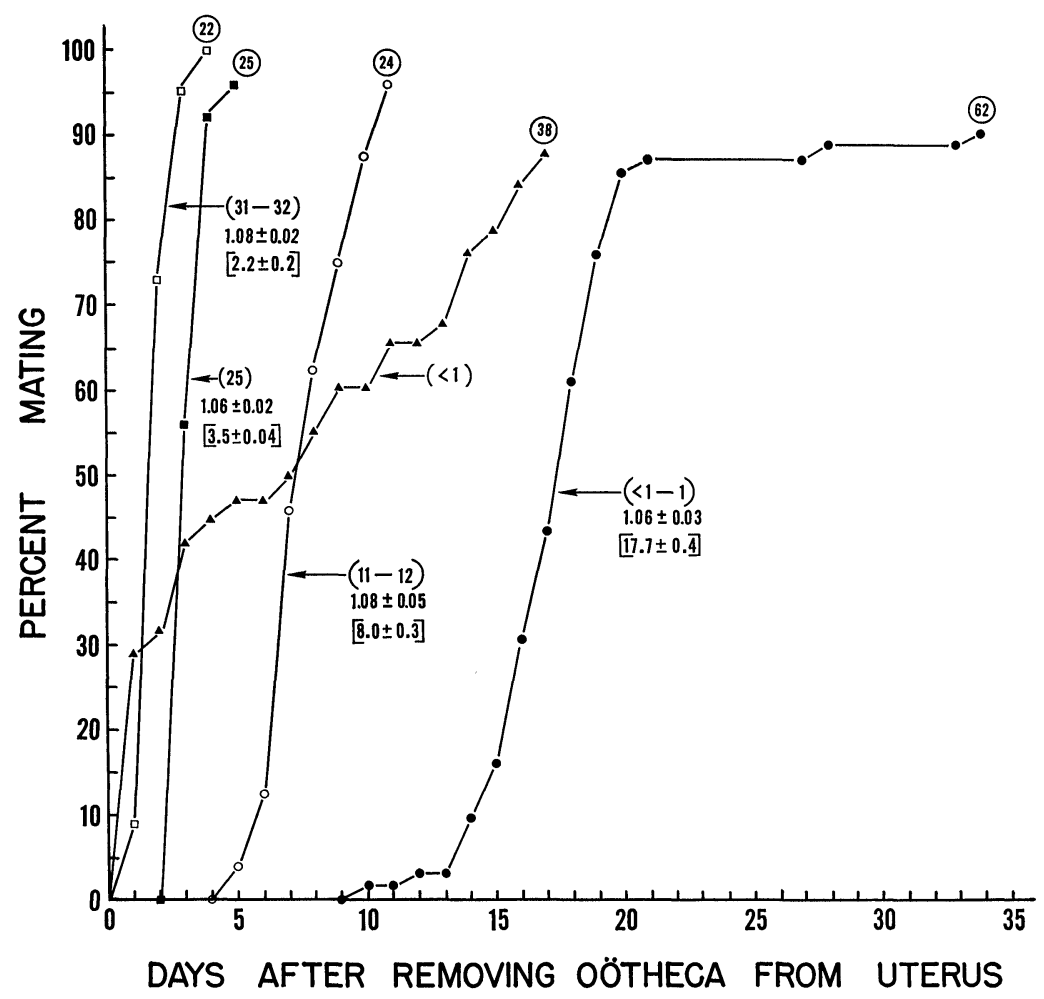

Fig. 12. Relationship between age of oötheca when removed from the uterus, and recovery of receptivity in $N$. cinerea. Numbers in circles $=$ number of insects used. Numbers in parentheses $=$ number of days females were pregnant when their oöthecae were removed. Numbers under the parentheses $=$ mean length $(\mathrm{mm}$. $) \pm$ standard error of the oöcytes measured $<24 \mathrm{hr}$. after mating. Numbers in brackets $=$ mean days \pm standard error for return of receptivity. Solid triangles $=$ virgin females; all other groups had mated prior to ovipositing. All females with males continuously until they mated; females examined daily for spermatophores. The per cent mating is expressed as accumulative data.

that fewer sperm are present in the smaller consecutively formed spermatophores. One experiment was performed to determine the oviposition behavior and subsequent receptivity of females that were mated to males that had mated consecutively; in all cases a spermatophore was transferred. Of I 50 females mated to virgin males, only 2 ( I \%) aborted their oöthecae prematurely and the eggs were 
unfertilized. Six (10\%) of 6I females mated to males that had mated previously within an hour aborted unfertilized eggs; thirteen $(8 \mathrm{r} \%)$ of 16 females that were mated to males that had mated twice within a few hours aborted their oöthecae. Subsequent receptivity, following parturition of females that were mated to virgin males or males that mated twice consecutively, was the same. Of I 32 females mated to virgin males, II $7(89 \%)$ were receptive after parturition; $52(93 \%)$ of 56 females that had mated males, which mated twice consecutively, were receptive; only 3 females (the others aborted unfertilized eggs) mated to males that mated 3 times consecutively, gave birth to normal sized litters, and these females mated again following parturition. Consecutive matings may affect female oviposition behavior because no sperm, or an insufficient amount of sperm enter the spermathecae from spermatophores formed during the second and third matings. However, if sperm are present and the eggs are fertilized, the mating behavior of females, following parturition, is the same whether they are mated to virgin males or males that mated 2 or 3 times consecutively; the spermatophores produced by the latter males presumably had fewer sperm.

\section{Effect of starvation on receptivity of females}

Thirty-six females were given food and water for $24 \mathrm{hr}$. only on the sixteenth day of pregnancy. After parturition (gestation averaged $39.0 \pm 0.6$ days) they were exposed to males and lab chow. Thirty-four (94\%) eventually mated and their oöcytes were $0.96 \pm 0.01 \mathrm{~mm}$. long $<24 \mathrm{hr}$. after mating. At parturition, the oöcytes of females starved during pregnancy are smaller than those in females that feed during gestation. In starved females, presumably the corpora allata do not become reactivated in late gestation, as they do in fed individuals (cf. fig. I). It was shown earlier that after parturition receptivity could be correlated with the size of the oöcytes; unreceptive females were those whose oöcytes were relatively

TABLE 5-Receptivity of females, mated to castrated males, which oviposited and whose oöthecae were removed after various periods of time

\begin{tabular}{|c|c|c|c|}
\hline $\begin{array}{l}\text { Age (days) of } \\
\text { oöthecae when } \\
\text { removed from uteri }\end{array}$ & $\begin{array}{c}\text { Days after removal } \\
\text { of oöthecae females } \\
\text { mated } \\
\text { (Mean } \pm \text { S. E.) }\end{array}$ & $\begin{array}{l}\text { Oöcytes }(\mathrm{mm} .) \\
(\text { Mean } \pm \text { S. E. })^{*}\end{array}$ & $\mathbf{N}$ \\
\hline $\begin{array}{c}16-18 \\
19-21 \\
33,34\end{array}$ & $\begin{array}{l}6.3 \pm 0.7 \\
3.6 \pm 0.4 \\
2.5 \pm 0.5\end{array}$ & $\begin{array}{l}1.21 \pm 0.06 \\
1.04 \pm 0.02 \\
1.02 \pm 0.07\end{array}$ & $\begin{array}{r}5 \\
10 \\
2\end{array}$ \\
\hline
\end{tabular}

* <24 hr. after mating. 
TABLE 6-Effect of nutrition on receptivity following parturition in $N$. cinerea

\begin{tabular}{|c|c|c|c|c|}
\hline \multicolumn{2}{|c|}{ Diet } & \multirow{2}{*}{\multicolumn{2}{|c|}{$\begin{array}{l}\text { Number used } \\
\text { and percent } \\
\text { mating }\end{array}$}} & \multirow{2}{*}{$\begin{array}{c}\text { Days after } \\
\text { parturition to } \\
\text { mate (Mean } \pm \text { S.E. })\end{array}$} \\
\hline Juring $g$ & after parturition & & & \\
\hline $\begin{array}{l}\text { lab chow } \\
\text { lab chow } \\
\text { starved§ } \\
\text { starved§ }\end{array}$ & $\begin{array}{l}\text { starved } \\
\text { lab chow* } \\
\text { starved }\end{array}$ & $\begin{array}{r}N \\
60 \\
105 \\
60 \\
128\end{array}$ & $\begin{array}{l}\% \\
85 \\
76 \\
98 \\
23\end{array}$ & $\begin{array}{l}0.7 \pm 0.1 \\
0.7 \pm 0.1 \\
2.8 \pm 0.2 \pi \\
3.5 \pm 0.4\end{array}$ \\
\hline
\end{tabular}

* Females that were fed were exposed to males and food $<24 \mathrm{hr}$. after parturition.

§ Given 9-10 days to mate after parturition.

I The oöcytes of these females were $0.94 \pm 0.02 \mathrm{~mm}$. long measured $<24$ hr. after mating.

large at the time the females gave birth. Therefore, one would expect that inanition during gestation, and subsequent feeding following parturition would affect female receptivity. The results of experiments to determine the effect of nutrition on receptivity in $N$. cinerea are shown in table 6 and figure 14. A high percentage $(85$ and $76 \%)$ that were fed during gestation, and were then starved or fed, mated again. In marked contrast, only $23 \%$ became receptive again if they were starved during and after gestation; in other experiments, as high as $40 \%$ of similarly starved females were receptive (fig. I6). It should be noted that the females were starved in groups; some females died and were partly or completely eaten during the night before they could be removed from the containers. This may have increased the percentage of females that became receptive again. However, in spite of this source of error, it is evident that starvation during gestation markedly reduced the number of females that regained their receptivity, provided the females were not fed after parturition.

$N$. cinerea females that are fed during gestation and become receptive after parturition, usually mate within a day after giving birth; this is true whether or not the females are fed after parturition. (table 6). However, females which are starved during gestation and are then exposed to males and food after parturition become receptive more slowly; $80 \%$ mated within 4 days after giving birth whereas a comparable percentage of females fed during gestation did so $<24 \mathrm{hr}$. after parturition (fig. I4). Only $23 \%$ of the females starved during gestation and after parturition mated within a 9 - IO day period and these averaged $3.5 \pm 0.4$ days to mate (table 6). When, after 9-10 days, the remaining females were 


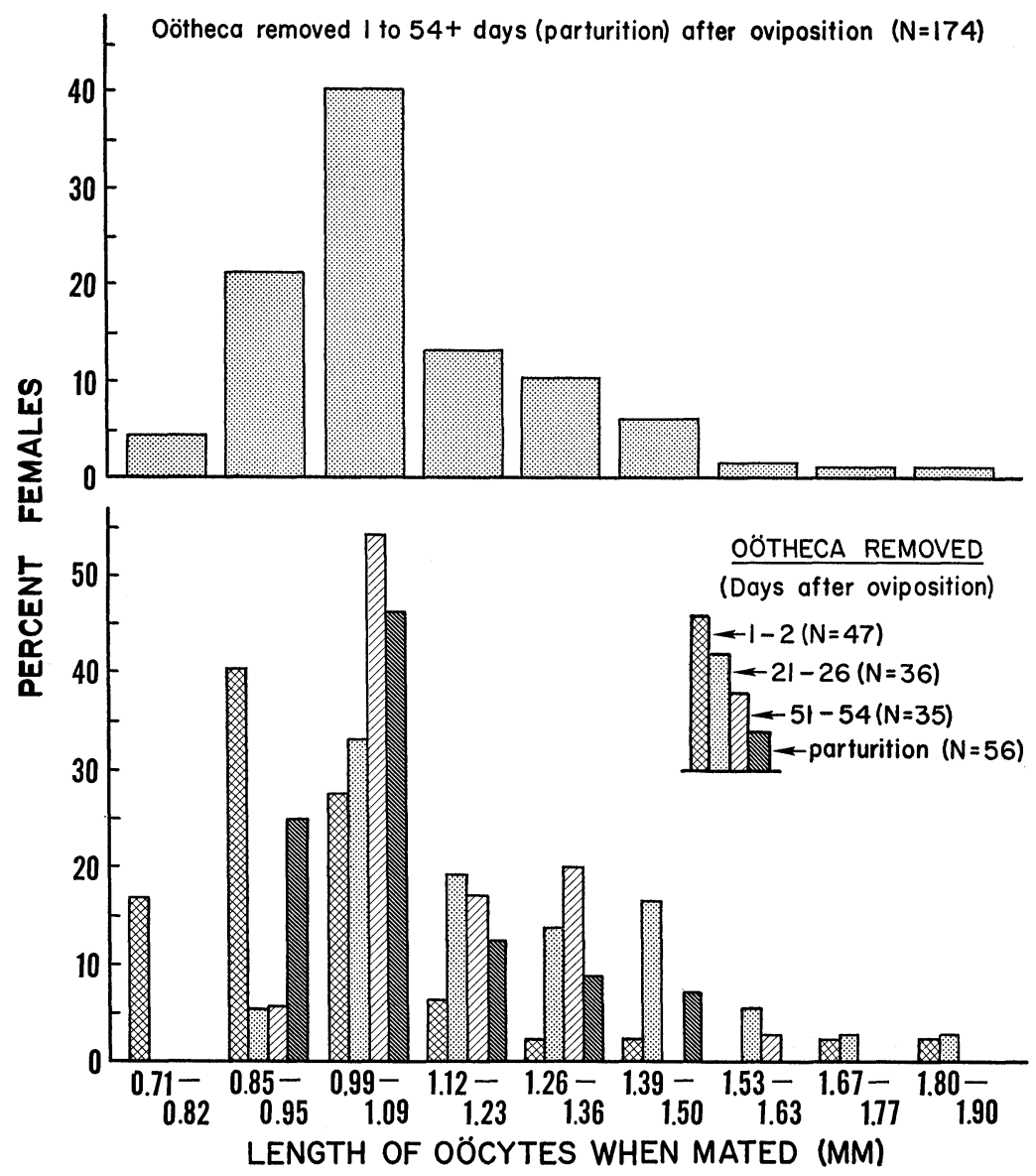

Fig. 13. Frequency distribution of lengths of oöcytes of females of $N$. cinerea that mated after their oöthecae were removed from the uteri. The parturition group was females that gave birth normally. The top histogram is a combined summary of all the groups shown in the figure below. (Room temperature.)

exposed to food for only $2 \mathrm{hr}$., the number of females that mated increased rapidly within the next 5 days (fig. I4); the oöcytes of females that mated after this meal were $0.88 \pm 0.01 \mathrm{~mm}$. long $(\mathrm{N}=20)$. An additional increase in mating occurred when the remaining females were fed again ad libitum (fig. I4); the oöcytes of Io of these females were only $0.86 \pm 0.02 \mathrm{~mm}$. long. The 


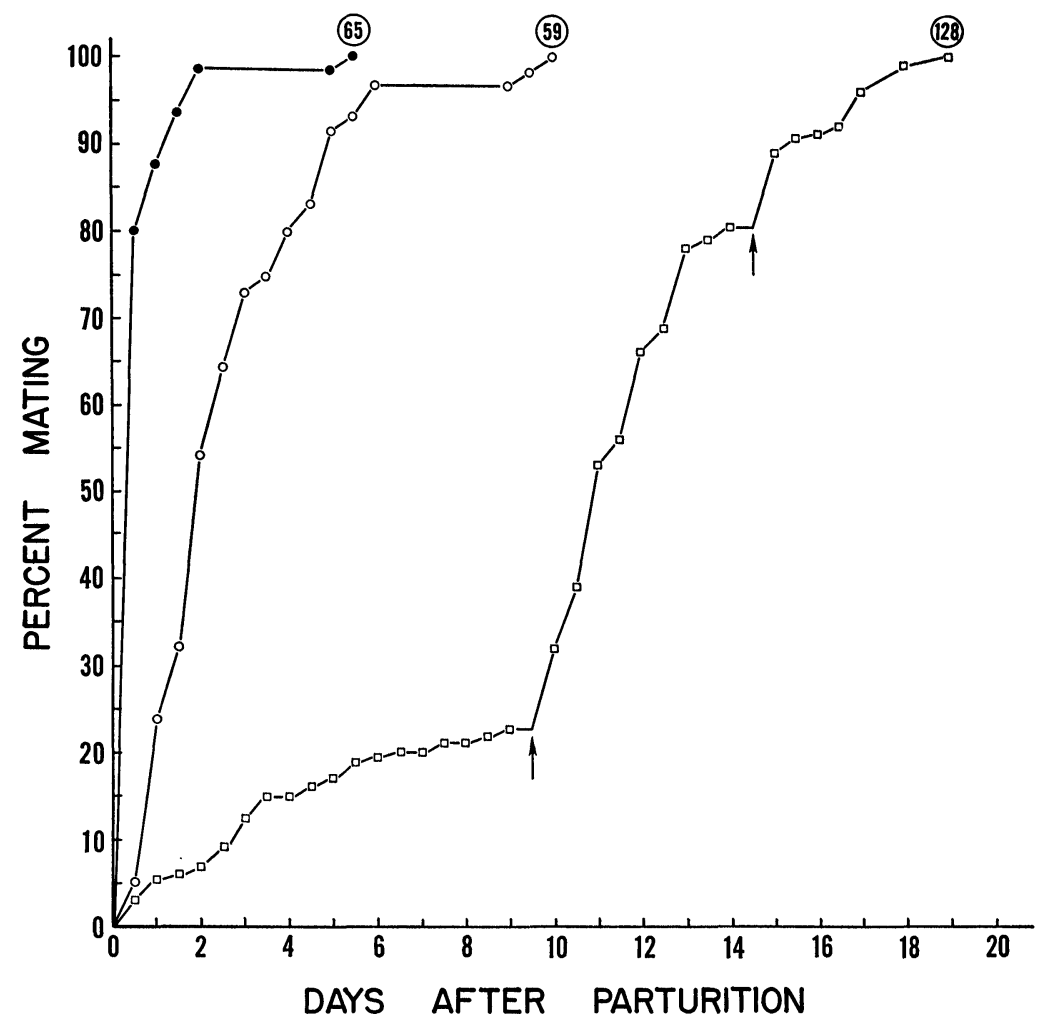

Fig. 14. Effect of starvation on receptivity of $N$. cinerea following parturition. Solid circles $=$ Females fed during gestation and after parturition; average days to mate after parturition was $0.7 \pm 0.3$. Open circles $=$ Females starved during gestation, then exposed to males and food after parturition; 59 of 60 females mated; average days to mate after parturition was $2.8 \pm 0.2$. Open squares $=$ Females starved during gestation and for 9-10 days after parturition, then fed; average days to mate prior to feeding was $3.5 \pm 0.4$. First arrow $=$ remaining females (i.e., those that did not mate) fed for $2 \mathrm{hr}$. only; average days to mate after feeding was $2.0 \pm 0.1$. Second arrow $=$ remaining females fed ad libitum; average days to mate after second feeding was $1.7 \pm 0.3 ; 128$ out of 136 females mated. Food was lab chow. Numerals in circles $=$ number of insects (based only on females that mated).

oöcytes of the females that mated after being fed for $2 \mathrm{hr}$. and then ad libitum did not contain yolk so that return of receptivity could not be correlated with corpora allata activity using oöcyte yolk as an indicator. 
Females that were starved during gestation and fed after parturition but were not mated again, oviposited in II-25 days $(\overline{\mathrm{x}}=\mathrm{I} 5.5 \pm 0.2$; fig. I 5 , bottom $)$. Females starved during gestation were exposed to males for $2-4$ hours within 2 days after parturition and the oöcytes of receptive (those that mated) and non-receptive individuals were measured. Non-receptive females had oöcytes that averaged $0.83 \pm 0.0 \mathrm{I} \mathrm{mm}$. $(\mathrm{N}=44)$ whereas the oöcytes of receptive females averaged $0.94 \pm 0.01 \mathrm{~mm}$. long $(\mathrm{N}=\mathrm{I} 6)$. The oöcytes were slightly larger in the receptive females, but receptivity could not be correlated with the presence of yolk in the oöcytes of all cases. Females, starved during gestation, were exposed to males for $2-4 \mathrm{hrs}$. within 2 days after parturition, and those that mated were separated from their partners before a spermatophore was transferred, thus insuring that there would be no effect of spermatophore stimuli on rate of oöcyte development (Roth, 1964). After being given food ad libitum, receptive females usually oviposited sooner than nonreceptive individuals (fig. I5, top). These results suggest that even though yolk was not present in the oöcytes of many of the receptive females, their endocrine system was more active than nonreceptive individuals.

\section{Effect of starvation and isolation from males on receptivity}

Females that were fed during and after gestation became unreceptive if they were isolated from males for several days after giving birth (fig. Io). Since receptivity can be correlated with the presence of small oöcytes, and starvation during gestation or after parturition affects the rate of oöcyte development, one would expect starved females to behave somewhat differently from fed individuals. Starved females, whose oöcytes develop slightly or not at all, should remain receptive for longer periods of isolation from males. The receptivity of starved females is shown in figure 16. As found previously (fig. IO) there was a marked decline in receptivity, of females fed during and after gestation, after 3-6 days of isolation from males (fig. I6A, lined bars). Females fed during gestation but starved after parturition also became nonreceptive with isolation but to a lesser extent than the fed group; about $29-36 \%$ were still receptive after 3-6 days of isolation (fig. 16A, stippled bars). About $40 \%$ of the females starved during gestation and after parturition were receptive (fig. I6B, stippled bars). Even after 5-6 days of isolation from males, $38 \%$ were still receptive. This is to be expected since in these females there is little or no oöcyte develop- 


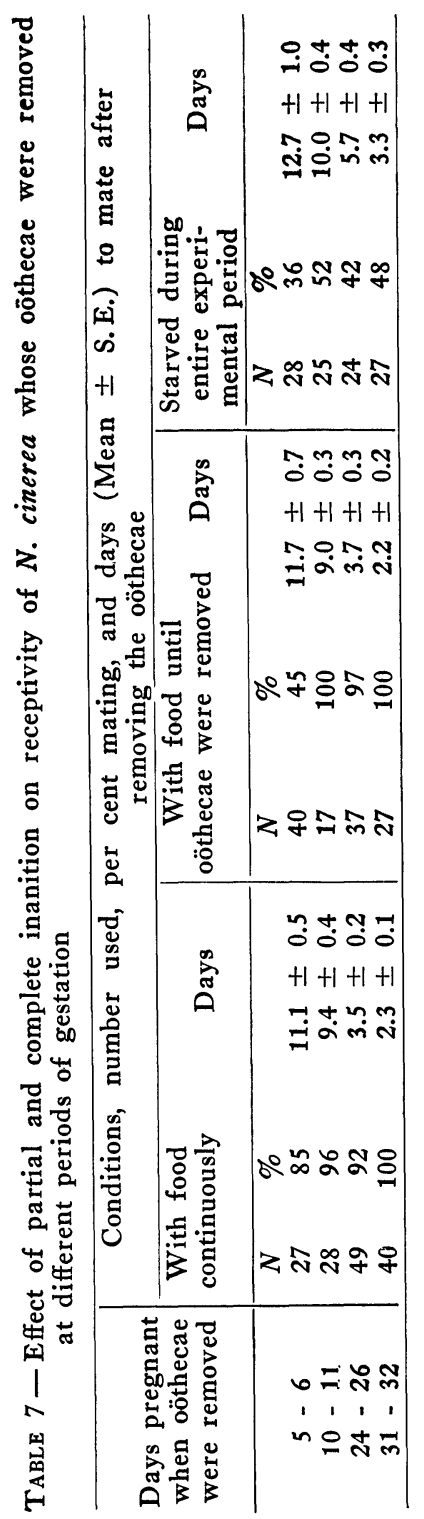


ment following parturition if starvation is continued. More than $25 \%$ were still receptive after 9 - Io days isolation from males and food. In the experiments with females starved during gestation and after parturition, only data from individuals that lived at least 5 days after being placed with males was used. However, starved females that mate after being isolated for several days after parturition do so almost immediately on being placed with males. The results with females starved during gestation but fed after parturition differed markedly from females fed during and after gestation. Ninety-eight per cent were receptive and this did not change even after 5- 6 days isolation from males (fig. I6B, lined bars). Sixtyfive per cent were still receptive after 7-8 days isolation and this dropped to $20 \%$ only after 9 - IO days of isolation. In all females that mated, the oöcytes averaged less than $1.5 \mathrm{~mm}$. long (fig. I6A, B).

Females of L. maderae which feed during and after gestation also become unreceptive if they are isolated from males; and as in $N$. cinerea, starvation after parturition prolongs receptivity (table 3 ).

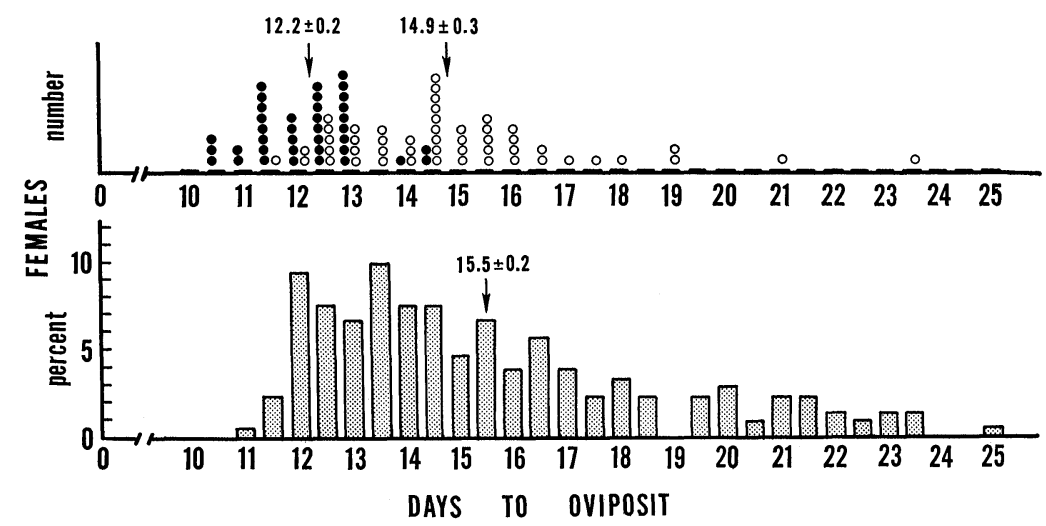

Fig. 15. Receptivity and oöcyte development following parturition in $N$. cinerea starved during gestation. Top: Females exposed to males and food after parturition. Solid circles $=$ receptive females. Open circles $=$ non-receptive females. Each circle represents one female. Days to oviposit calculated from time of exposure to food. Bottom: Females that were not exposed to males after parturition. $(\mathrm{N}=213)$. Days to oviposit calculated from time of parturition; females were given food within a day after giving birth. Numbers above the arrows indicate the average number of days \pm standard errors taken to oviposit by the various groups of females. 
Effect of partial and complete starvation on receptivity after removing the oöthecae from the uteri

The time taken for return of receptivity, after the oötheca is removed from the uterus, varies with the length of the gestation period at the time of removal of the egg case (figs. II, I2). The effect of partial and complete inanition on return of receptivity following removal of the oötheca is shown in table 7. Females fed for IO-II, 24-26, and 3I-32 days before having their oöthecae removed behaved like control females that were fed lab chow continuously. However, only $45 \%$ of the females fed for 5-6 days only, mated. There was a marked drop in the number of females that mated $(36-52 \%)$ in all 4 groups of females starved during the entire experimental period. The females that were fed for only 5- 6 days behaved like completely starved females. Regardless of the extent of feeding or starvation, time taken to mate after removing the oöthecae was similar or only slightly delayed in females starved during the entire experiment. The lengths of the oöcytes of the females that did not mate, in the groups with $52 \%$ or less receptive, are shown in table 8. The oöcytes, in practically all of these nonreceptive females, were undeveloped and lacked yolk.

\section{Effect of starvation and mating, following parturition, on oöcyte development in females fed during gestation}

Females of $N$. cinerea fed during gestation were fed or starved after giving birth. These females were not mated again, and the time taken to oviposit was determined. The results in table 9 show that the average number of days taken to oviposit was about the same for both groups ( 8.5 and 9.2 days for the fed and starved groups, respectively). However, 13\% of the starved females took I I. 5 - I 5 days, whereas only I $\%$ of the fed group required II.5 days to oviposit and none took longer. Starvation following parturition had only a slight or no effect on the rate of oöcyte development if females were fed ad libitum during gestation. Females that mated after parturition and were either fed or starved during their second preoviposition period did not oviposit sooner than comparably treated nonmated females (table 9); in fact, the mated females took slightly longer to oviposit. Thus, when females have access to food during the entire gestation period, the oöcytes mature at a rapid rate if fed or starved after parturition and an additional mating after the female gives birth does not affect this rate of development. The 

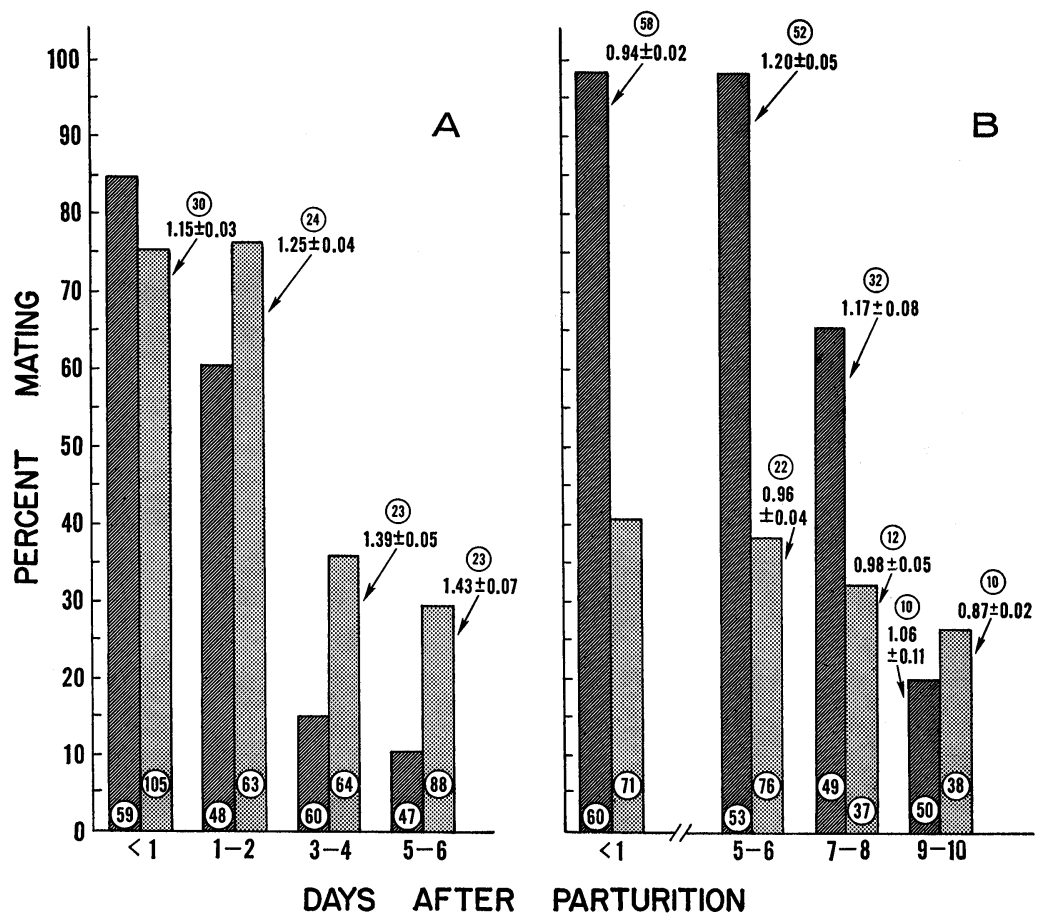

Fig. 16. Effect of starvation and delayed exposure to males on receptivity of females following parturition in $N$. cinerea. A-Fed during gestation. $B$ - Starved during gestation. The axis of abscissas indicates the days after parturition females were placed with males. Lined bars $=$ fed after parturition. Stippled bars $=$ starved after parturition. Numerals in circles within the bars $=$ number of females used. Numerals opposite the bars $=$ length of oöcytes $(\mathrm{mm}$.) \pm standard errors of females that mated, measured at the time of, or $<24 \mathrm{hr}$. after copulating; numerals in circles outside the bars = number of females whose oöcytes were measured. Gestation period of all the females was 35-40 days. Females fed during gestation and those starved during gestation but fed after parturition were kept with males until they mated or oviposited. Females starved during gestation and after parturition were allowed up to 10 days after parturition to mate.

slightly longer period taken for mated females to oviposit in these experiments probably indicates that the females that became receptive and mated had smaller oöcytes than the unmated females at the time of parturition.

L. maderae differs from $N$. cinerea in that starvation after partu- 


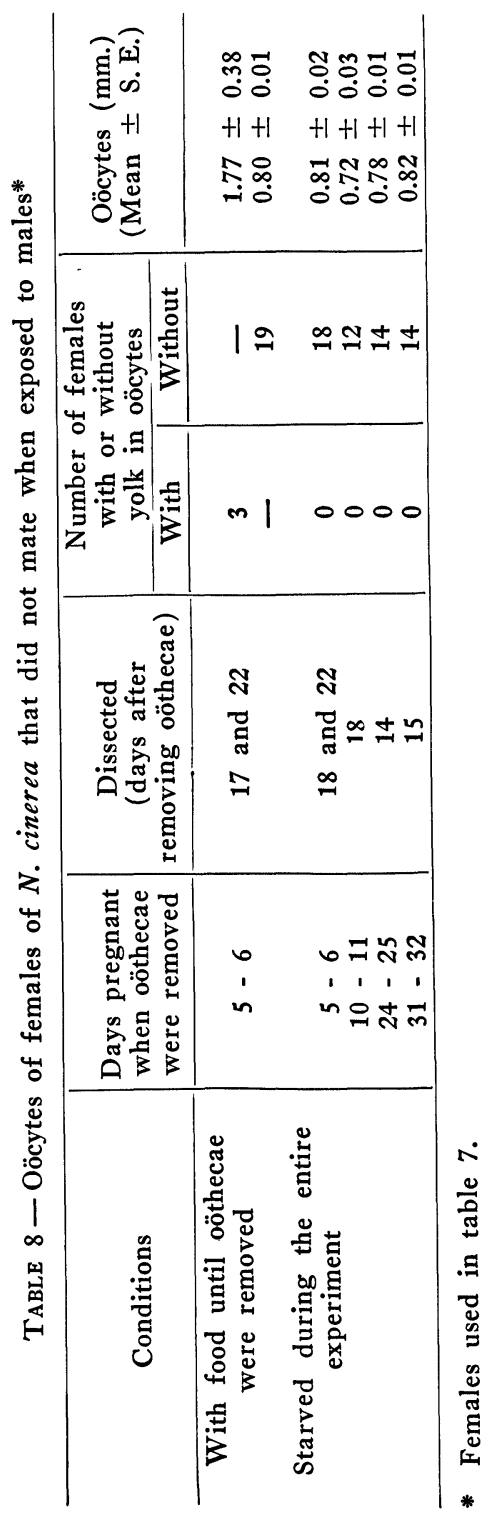




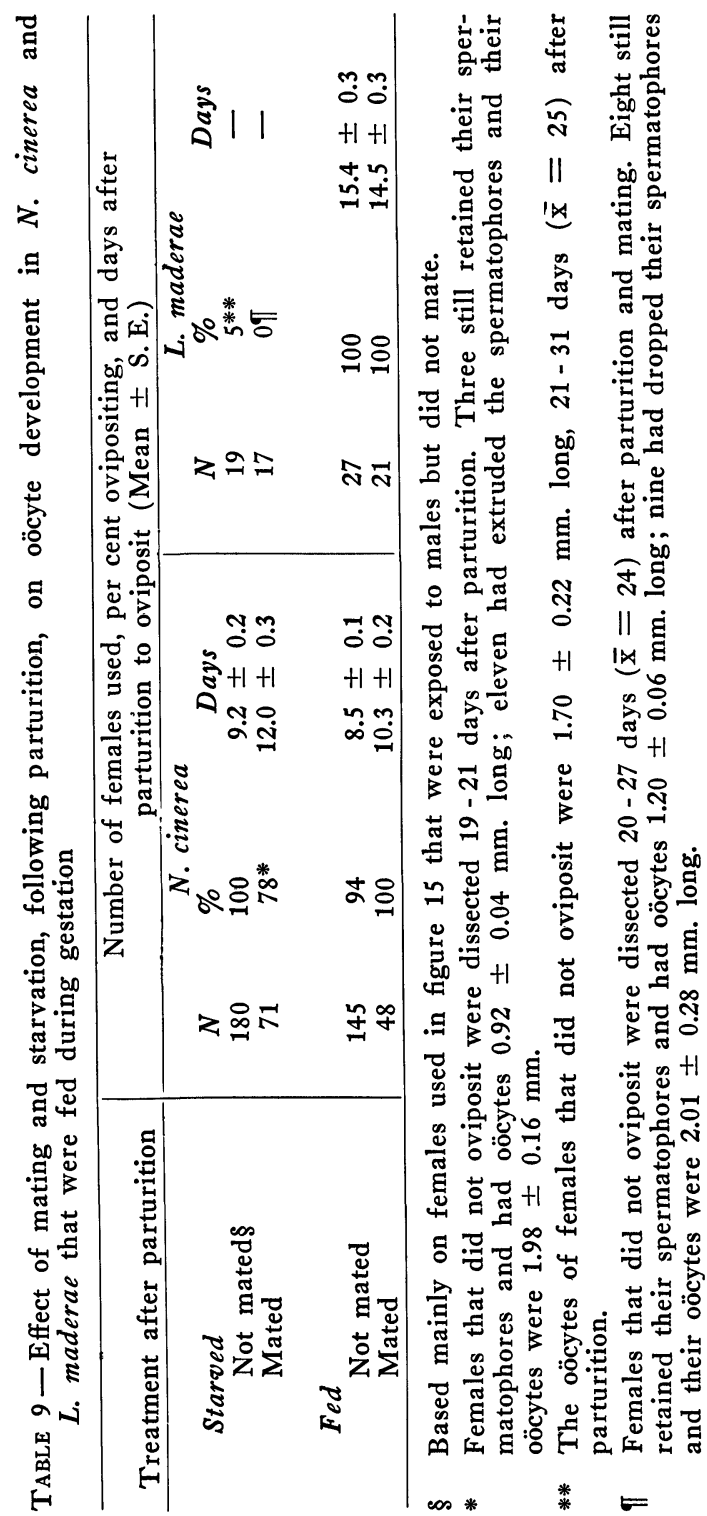


rition, in females fed during gestation, inhibits oöcyte development; mating does not result in oöcyte development in these starved $L$. maderae (table 9).

\section{Effect of nutrition and mating, following parturition, on oöcyte development in females starved during gestation}

The effect of exposing females, which were starved during gestation, to food for various periods of time following parturition is shown in table Io. If not mated, only 6 and $10 \%$ of the females oviposited when given food for $\mathrm{O}$ and I day. Mating similarly treated females did not increase the percentage ovipositing. When fed for 2 and 3 days, the number ovipositing increased to 22 and $39 \%$, respectively, and mating further increased the number ovipositing to 53 and $69 \%$. Mating had no effect on the percentage ovipositing after the females had access to food for 5 days; however, after this amount of feeding as high as $68 \%$ of the nonmated females oviposited. Seventy-one to $100 \%$ of the females oviposited if they were fed for $6-12+$ days (table Io). The average time taken to oviposit was very similar in all the females that oviposited regardless of the length of time they had access to food. Also, the time taken to oviposit by the mated females was the same as the nonmated females only the percentage of females ovipositing differed in the groups fed for 2 and 3 days.

The oöcytes of the females that were starved after parturition and were not mated again averaged only $0.77 \pm 0.02 \mathrm{~mm}$. ( 13 of the 29 females were dissected). The oöcytes of the remaining 6 nonmated females, from all groups, which did not oviposit ranged from undeveloped to practically mature, the latter occurring in the small number of individuals that were fed for 8-10 days before being starved. Thirty-seven $(4 \mathrm{I} \%)$ of the females had oöcytes that were less than $\mathrm{I} \mathrm{mm}$. long and lacked yolk. Twenty-eight (3i $\%)$ had oöcytes in various stages of resorption.

The oöcytes of the 20 mated females that did not oviposit averaged $0.98 \pm 0.08 \mathrm{~mm}$. after they were starved continuously after parturition; all still retained their spermatophores when dissected. In the remaining groups, the 56 mated females that did not oviposit had oöcytes that varied considerably in size 25 days after parturition. Thirty-one $(55 \%)$ still retained their spermatophores and their oöcytes averaged I.19 $\pm 0.09 \mathrm{~mm}$. The 25 females that had dropped their spermatophores had oöcytes that averaged $\mathrm{r} .84 \pm 0.13$ $\mathrm{mm}$. long. Forty-four nonmated females which were fed for 2, 3, 
T'ABLE $10-$ Effect of nutrition and mating, following parturition, on oöcyte development in $N$. cinerea that were starved during gestation

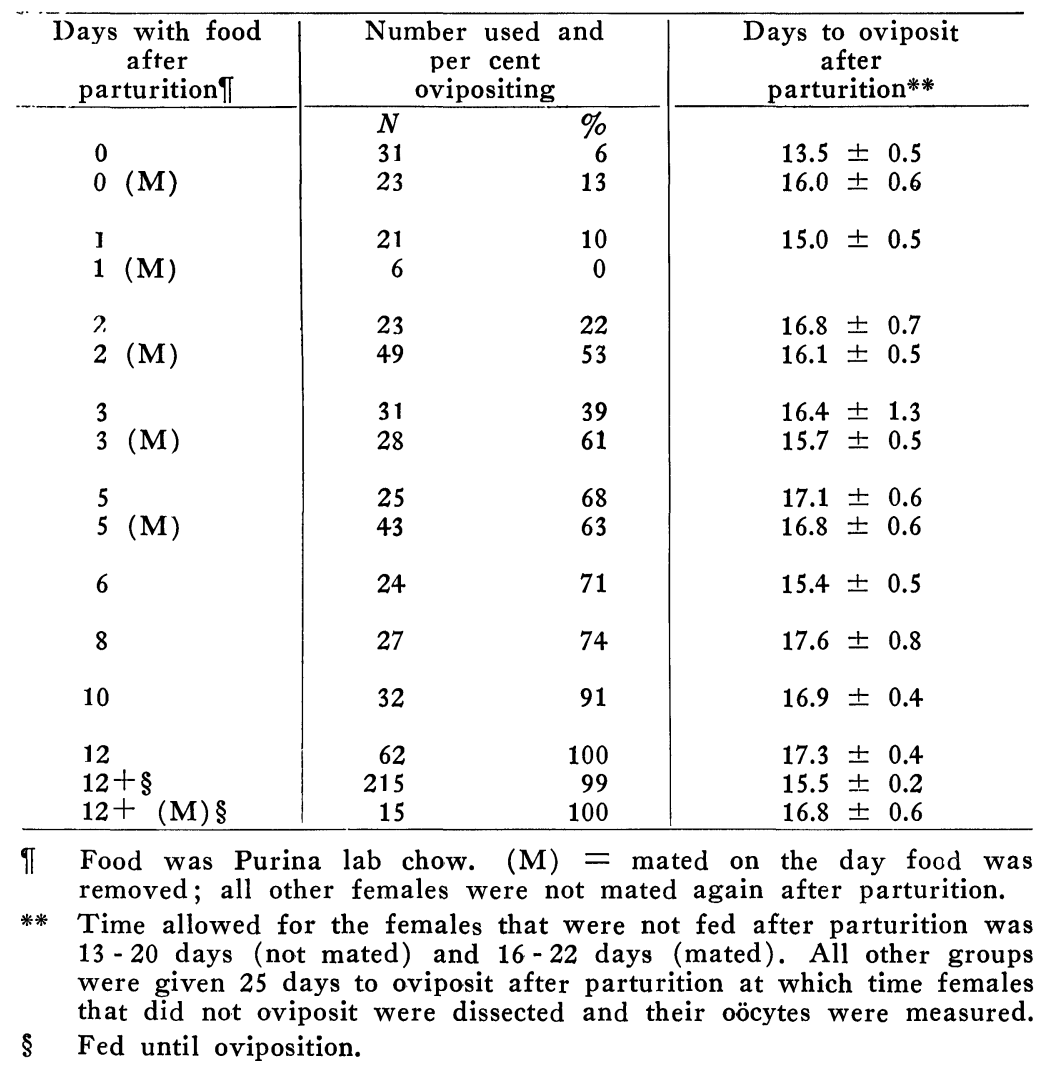

and 5 days (comparable to the mated groups) had oöcytes $1.23 \pm$ $0.08 \mathrm{~mm}$. long. The larger size of the oöcytes in mated females that dropped their spermatophores is indicative of a higher concentration of corpus allatum hormone than that found in the females that failed to drop their spermatophores or in those that were not mated.

The results show that when females are starved during gestation and not mated after parturition, exposure to food for at least 5 days is required for more than $60 \%$ of the individuals to oviposit. The stimulus afforded by mating has little or no effect on oöcyte development if the females are starved continuously, or if given food for only I day after parturition; the mating stimulus did increase the 
percentage of females that oviposited if the females were first fed for 2 or 3 days after parturition.

Effect of partial and complete starvation, and mating, on oöcyte development following removal of the oöthecae at different periods of gestation

Given an adequate diet during gestation and after parturition, an additional mating did not affect the rate of oöcyte development. If oöthecae were removed during gestation, the oöcytes matured prematurely. A series of experiments were performed to determine the effect, if any, of partial and complete starvation and mating on oöcyte development in $N$. cinerea after their oöthecae were removed at different periods in gestation. The results are shown in tables I I and 12. Practically all females that were fed continuously oviposited. Mating increased the rate of oöcyte development, only in females whose oöthecae were removed 5-6 and IO-II days after oviposition; mated females oviposited on an average of 3 or 4 days earlier than nonmated individuals. Partial starvation (those starved only after their oöthecae were removed) markedly reduced the number of nonmated females that oviposited. Virtually all females that were fed for 5-6 and IO-II days only, and then had their oöthecae removed and were starved, failed to oviposit if they were not mated again. The percentage of ovipositing females that were starved after their oöthecae were removed 25-44 days after ovulation, was lower than those fed during the entire experiment. Partial starvation also slightly retarded the rate of oöcyte development (as indicated by time of oviposition) in females whose oöthecae were removed prior to parturition. Mating increased the percentage of females that oviposited in the 4 similar groups whose oöthecae were removed 5-32 days after oviposition. Of I IO females starved throughout the experiment, only $8(7 \%)$ oviposited after their oöthecae were removed 5-32 days after oviposition. Of these I IO females, $24 \%$ (including the 8 that oviposited) had yolk in their oöcytes when dissected (table 12). Of the 46 females in the comparable mated group that were starved during the whole experimental period, i 8 (39\%) oviposited and an additional I6 females had yolk in their oöcytes; thus, $74 \%$ had yolk in their oöcytes after mating. Of the 28 females that did not oviposit, $16(57 \%)$ still retained their spermatophores when dissected, indicating insufficient amount of corpus allatum hormone to affect the spermathecal glands whose secretion facilitates extrusion of the spermatophore (Engelmann, I960a; Roth and Barth, 1964). 


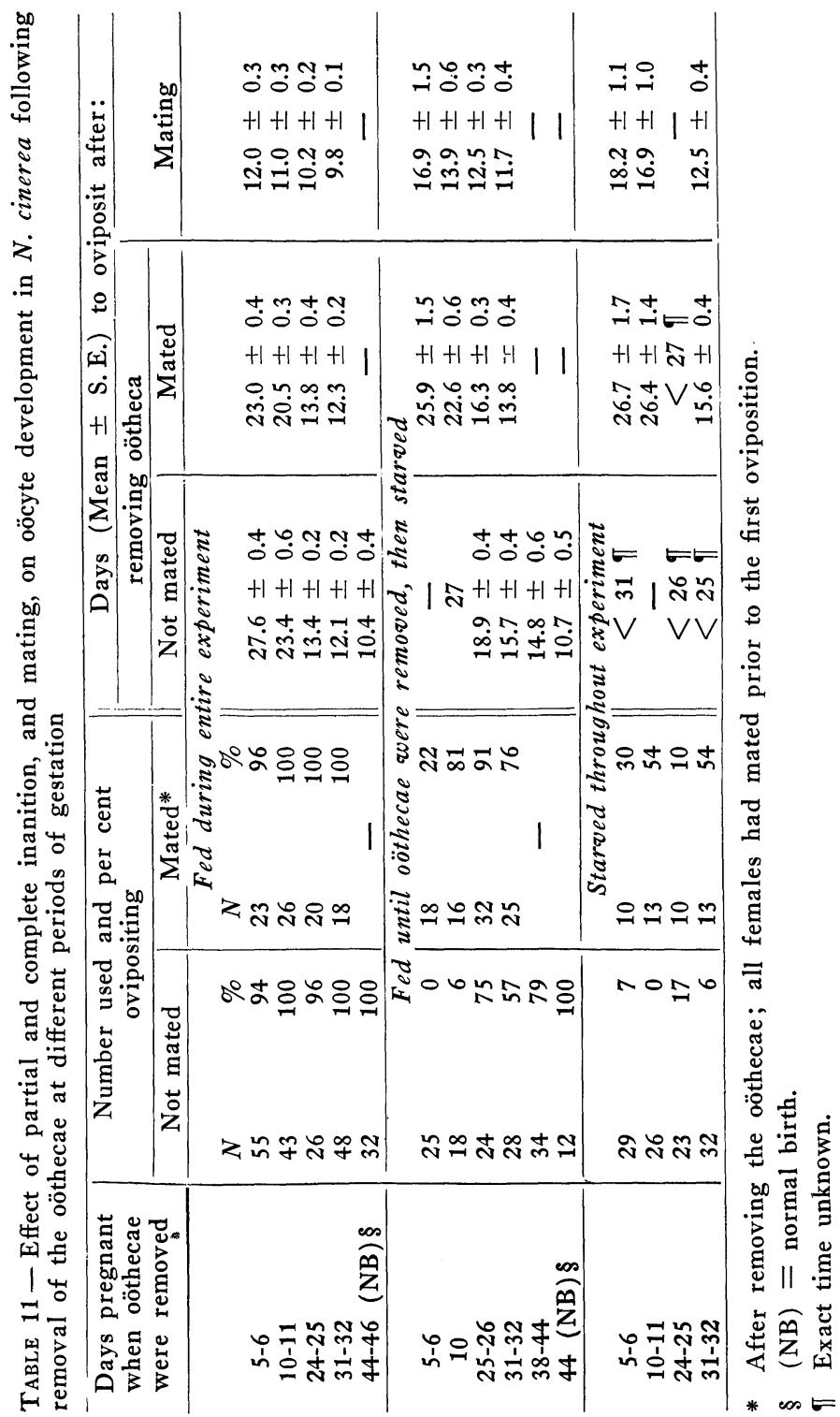




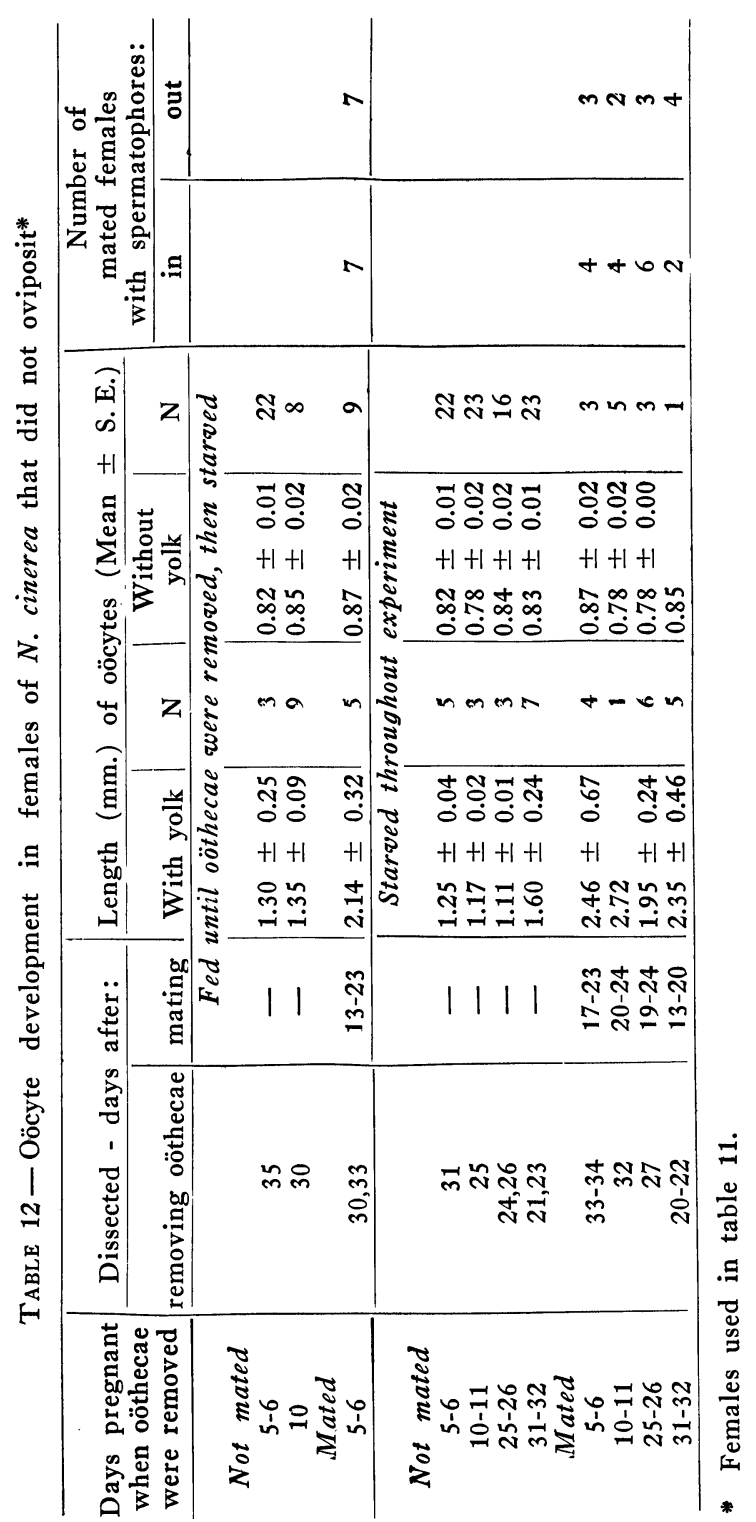


These experiments show that partial or complete starvation affected the resumption of oöcyte development when the oötheca was removed from the uterus at different periods in gestation. In partially fed females the effect was greatest (fewer females oviposited and developed yolk), the shorter the exposure to food (i.e., when the oöthecae were removed 5-6, or Io days after oviposition and the females were then starved). In totally starved females the effect was about the same, regardless of when the oöthecae were removed; $0-17 \%$ oviposit. In both partially and completely starved females, mating had a stimulating effect and increased the percentage of females that oviposited and had yolk deposited in the oöcytes.

\section{DISCUSSION}

During gestation the female remains unreceptive, apparently because mechanical stimuli resulting from the oötheca in the uterus prevents the receptivity center from being reactivated. Thus, if the nerve cord is transected in a pregnant female, the inhibitory signals from the uterus are interrupted, the receptivity center becomes activated and after a few days the female mates again in spite of the fact that she is carrying an oötheca. The return of receptivity in females whose oöthecae are removed at different periods in gestation usually, but not always can be correlated with onset of corpus allatum activity, as indicated by yolk deposition in the oöcytes. However, $N$. cinerea mate even if they are allatectomized $<6 \mathrm{hr}$. after emergence or have their inactive corpora allata removed during pregnancy; the latter females mate after parturition (Roth and Barth, 1964). Roth and Barth suggested that some event, possibly the release of neurosecretion, which occurs at about the same time as onset of corpus allatum activity, determines whether or not the female will accept the courting male.

Engelmann (I96ob) observed that some females of L. maderae do not mate (but their oöcytes mature) even though they have access to males. He concluded from his observations that ". . . the corpus allatum hormone must be present in low titer to stimulate the responsiveness of the female. A high titer of the hormone has no effect since, fr m a total of 80 females, none mated that had oöcytes exceeding a size of $1.46 \mathrm{~mm}$. Apparently as soon as a certain titer is surpassed, the female does not accept the male any more." Since in Engelmann's experiment the females had constant access to males, his conclusion that females will not mate when corpus allatum hormone is high is not warranted because these nonreceptive females did not mate 
even when their hormone concentration was low. In addition, virgin allatectomized $L$. maderae do mate if they are exposed to courting males (Roth and Barth, 1964); presumably the corpus allatum hormone concentration is very low or nonexistent in these females.

There may be a decided difference in oöcyte size at mating in $N$. cinerea during the first preoviposition period as compared with that following parturition. Although virgin females usually mate when their oöcytes first begin to show yolk deposition, they remain receptive (if isolated from males) even though their oöcytes continue to grow (Roth, 1964). This is also true in L. maderae (Roth and Stay, I962b). Receptivity of females of $N$. cinerea following parturition differs in that those with well developed oöcytes at the time of parturition, or those isolated from males for 2 or more days after giving birth (and consequently have large oöcytes) are or become unreceptive. Virtually all females of $L$. maderae become receptive shortly after birth. In this species the oöcytes do not contain yolk at parturition (Roth and Stay, I962b). However, L. maderae is similar to $N$. cinerea in that females usually become unreceptive if they are not given access to males a week after parturition. If, as suggested, neurosecretion is responsible for receptivity, it appears that the concentration of the hormone is critical only after parturition but not during the first precopulatory period (i.e., in the virgin female). Perhaps a high titer of neurosecretion does not inhibit receptivity in the virgin female but may prevent mating after parturition in oncemated females. It has already been shown in $N$. cinerea (Roth, 1964) that the effect of a particular reproductive stimulus may vary depending on the period in the reproductive cycle in which it occurs; for example, uterine stretching inhibits mating and oöcyte development after oviposition (i.e., during gestation) but is not effective when exerted during the first preoviposition period.

Ovariectomized virgin females of $N$. cinerea mate a few days after emergence but most of them do not become receptive again even 2 months after the initial mating; this is longer than the time required for normal gestation. In Leucophaea ovariectomy results in hypertrophy of the corpora allata and, as a result, the normal cyclical activity of the corpora allata (i.e., active during preoviposition and inactive during gestation) does not occur (von Harnack and Scharrer, 1956). The oötheca in the uterus is undoubtedly largely responsible for the cyclical activity of the corpora allata (Engelmann, 1957a, Roth and Stay, 1959, 1962b). It is possible that the neurosecretory system of the brain also continues to be active 
in ovariectomized females, and, if it controls receptivity it may explain our results with mated $N$. cinerea females whose ovaries were removed. Continued neurosecretory activity and the resulting high titer of hormone may tend to inhibit female receptivity for an abnormally long period. When oviposition is simulated by inserting glass tubes in the uteri of mated ovariectomized females and the inserts are removed after a few days, more females become receptive much more quickly than mated ovariectomized females that were not subjected to this treatment. Perhaps the insertion of the glass tubes resulted in stimuli that inhibited the neurosecretory system, thus preventing an increase in hormone titer. Upon removal of the artificial oötheca, the system is reactivated and the female mates. Thus, the results suggest that some center must first undergo a period of inactivity, induced by the oötheca in the uterus, for receptivity to return rapidly after parturition, or after removal of the egg case.

The hypothesis that a low concentration of a hormone activates and a high titer inhibits a receptivity center could also explain why some females are unreceptive after parturition. These would be the individuals whose neuroendocrine systems become active in late gestation. Theoretically, these females should have become receptive in late gestation since they would have gone through a period when their hormone titer was sufficiently low to induce receptivity. That they do not mate in late gestation may be explained by the mechanical stimulation, resulting from the oöthecae in the uteri, which suppresses mating behavior. That the same females do not mate even after parturition may be explained by assuming that the hormone titer has increased beyond the critical concentration necessary to induce receptivity. A high hormone titer would also explain why females become unreceptive after being isolated from males for several days after parturition. Nutrition may act as a "trigger" stimulus to the neuroendocrine system (de Wilde, I96I). This could account for the prolongation of receptivity when females are starved during gestation and after parturition; presumably the absence of nutritional stimuli prevents the accumulation of neurosecretion and its consequent inhibition of receptivity.

Females of $D$. punctata usually mate just after they emerge from the last nymphal skin, when they are still white and teneral. If isolated from males at emergence, the females tend not to mate (Stay and Roth, 1958). The mechanism governing this behavior is unknown. It cannot be correlated with increased activity of the corpora 


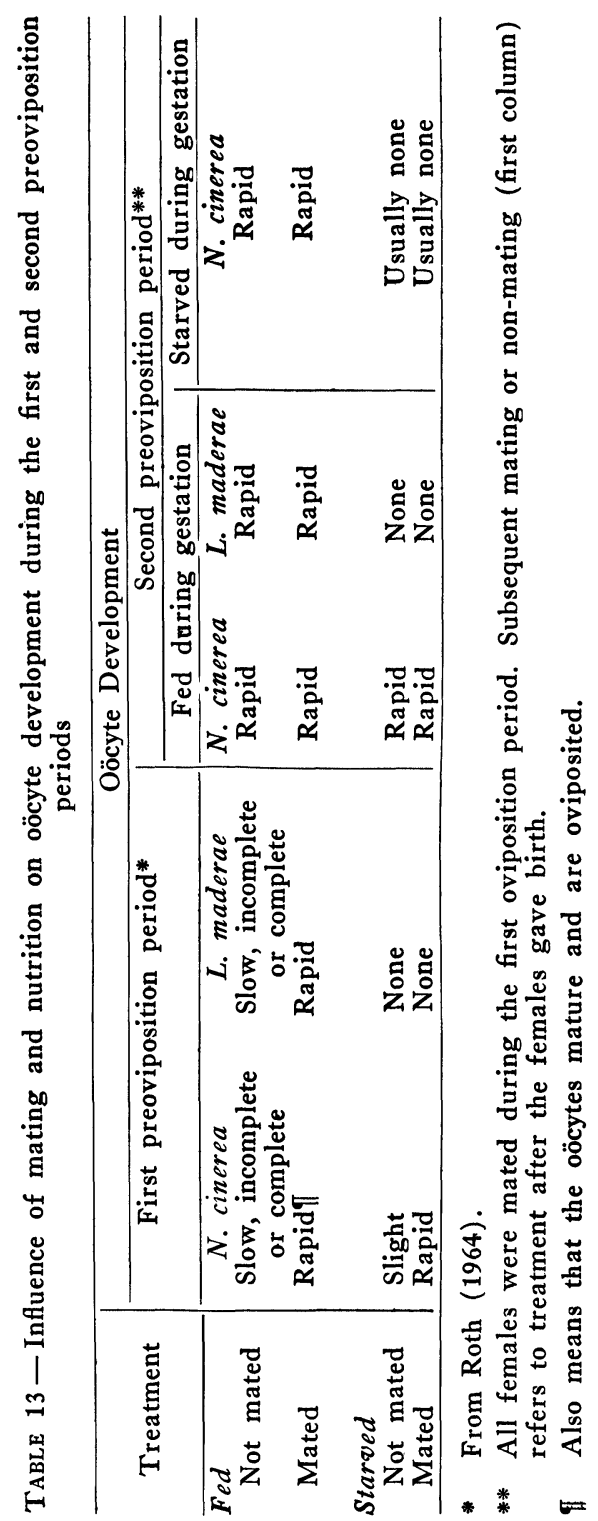


allata since these endocrines remain inactive in most virgin females and the oöcytes fail to develop (Engelmann, 1959; Roth and Stay, 1961).

The influence of mating and nutrition on oöcyte development in most females during the first and second preoviposition periods is compared and summarized in table I3. If females of L. maderae are starved during the first preoviposition, their oöcytes fail to develop even if the individuals are mated. In virgin $N$. cinerea the oöcytes develop only slightly if the females are starved but mating results in sufficient stimulation (via the brain) of the corpora allata so that the oöcytes mature in about the same time as fed-mated controls. In fed females of both species, mating and feeding stimuli act synergistically to activate the corpora allata to their fullest extent so that the oöcytes mature at their maximum rate (Roth, 1964).

After parturition, the oöcytes in normally fed individuals of $N$. cinerea and L. maderae mature rapidly and mating does not increase the rate of maturation. The effect of starvation following parturition, in females fed during gestation, differs between the 2 species. In $N$. cinerea the oöcytes mature rapidly even though the females are starved and not mated again. In marked contrast, the oöcytes of $L$. maderae are inhibited after parturition if the females are starved and an additional mating does not affect this inhibition. In $N$. cinerea mating has a stimulating effect on oöcyte development if females are starved during gestation and are then given food for 2 and 3 days only, after parturition (table Io). However, mating has no effect if the females starved during gestation continue to be starved, or are given food for only one day after giving birth. These results are in accord with the hypothesis (Roth, 1964) that mating stimuli are effective in further stimulating the corpora allata only if the corpora allata have reached a certain level of activity, or if activating stimuli to the corpora allata have begun to occur as a result of nutritional factors. This hypothesis also would explain the results obtained when oöthecae were removed from the uteri at different periods of gestation and the females were then starved (table II).

The corpora allata of cockroaches which incubate their eggs internally are inhibited during pregnancy and the oöcytes increase only in length and usually yolk is not deposited (Roth and Stay, I962b). However, in Diploptera punctata (Eschscholtz) (Engelmann, I959; Roth and Stay, 196r) and N. cinerea (Roth and Stay, 1962b), the corpora allata may become active a few days before parturition and 
yolk is deposited in the oöcytes while the female still has an oötheca in the uterus. Engelmann believed that in L. maderae inhibition of the corpora allata during pregnancy was due to a humoral factor from the eggs in the oötheca (Engelmann, I957a, b), and mechanical stimulation of the genital apparatus by the egg case, plus a "nonspecific" substance from the uterine eggs (Engelmann, I960a). More recently (Engelmann, I964) he suggests that inhibition is caused by a specific or nonspecific agent released by the egg case or the brood sac; this agent acts on neurones in the ventral nerve cord and brain which influence regions in the brain that in turn inhibit the corpora allata. Roth and Stay ( 1959, I96I, I962a, b) concluded that mechanical stimuli alone resulting from the stretched uterus could account for inhibition of the corpora allata during pregnancy.

The experimental inhibition of the corpus allatutm by introducing glass oöthecae in the uteri of $N$. cinerea and $P$. surinamensis does not support Engelmann's last hypothesis. Engelmann (1964) concluded from his observations on $L$. maderae that the insertion of an artificial oötheca into the uterus reduces the female's food intake. Since fasting or reduced food consumption inhibits the corpora allata and egg development, he questions the conclusion, based on the insertion of an artificial oötheca, that inhibition of the corpora allata by the oötheca is exclusively by a nervous pathway. Although this may be the case in $L$. maderae, the oöcytes in $P$. surinamensis that have wax oöthecae inserted in their uteri, mature after nerve cord transection (see figs. I3A, B, in Roth and Stay, I962b) and do not mature if the nerve cord is intact. It is true that in most pregnant females of $N$. cinerea the oöcytes do not mature if their oöthecae are removed very early in gestation and the individuals are then starved (tables II, I2). However, the oöcytes of females which have their oöthecae replaced by a glass tube $<24 \mathrm{hr}$. after oviposition eventually develop almost to maturity like normal pregnant controls (fig. 3); this would not have occurred if the glass oöthecae had prevented feeding. The lack of oöcyte development during pregnancy in $N$. cinerea and $P$. surinamensis can be explained by the hypothesis that mechanical stimulation alone, resulting from the presence of the oötheca in the uterus, inhibits the corpora allata.

Roth and Stay (1962a, b) have suggested that pressure changes resulting from the increasing size of the oötheca in the uterus tend to prevent or retard adaptation of mechanoreceptors, or the central nervous system, so that the corpora allata are inhibited during most of the gestation period. In Blaberus craniifer Burmeister, Byrsotria 
fumigata (Guérin) and the bisexual strain of Pycnoscelus surinamensis with unfertilized eggs in the uterus, the oötheca does not increase markedly in size because the eggs do not develop, inhibition of the corpora allata ceases prematurely, and consequently the oöcytes develop in spite of the presence of the egg case (Roth and Stay, I962b). The earlier return of corpora allata activity in some females of $N$. cinerea with glass tubes in the uteri (figs. 3, 4) may be due to the fact that there is no change in size of the uterus. A glass oötheca might be likened to the presence of unfertilized eggs in the brood sac. In both strains of $P$. surinamensis the glass rods were more effective inhibitors than the beads. Perhaps the shape of the insert, in this species, influences the degree of inhibition; the shape of a glass rod is more like an oötheca than is a bead.

During normal pregnancy, the length of time the corpora allata are inhibited differs between $P$. surinamensis and $N$. cinerea. Inhibition frequently ceases shortly before parturition in $N$. cinerea and only after parturition in $P$. surinamensis. The species difference might account for the greater effectiveness of glass rods in inhibiting the corpora allata in $P$. surinamensis.

\section{SUMMARY}

During gestation in $N$. cinerea the mechanical presence of the oötheca inhibits sexual receptivity. The prerequisites for the return of receptivity in the normal period of time, after oviposition or parturition, are: I) the presence of an oötheca (i.e., uterine stretching for at least a short period, and then 2) the removal of the oötheca (i.e., the stretch stimuli).

Return of receptivity can usually be correlated with the beginning of yolk deposition in the oöcytes. But the corpora allata do not control receptivity since allatectomized females mate. As shown for the first preoviposition period, return of receptivity after parturition is correlated with some event that occurs at about the same time as onset of corpus allatum activity. Some center, perhaps affected by the neurosecretory system in the brain, controls receptivity by controlling the response of "the female to the male's pheromone.

Females of $N$. cinerea which mate after giving birth have small oöcytes; females which do not mate have large oöcytes. After parturition, in $N$. cinerea and L. maderae, the oöcytes mature rapidly, and the females become unreceptive, if they are isolated from males for several days. The data suggest that a high hormone (neurosecretion?) titer, after parturition, may inhibit receptivity. 
Given an adequate diet during gestation and after parturition, an additional mating does not increase the rate of oöcyte development in $N$. cinerea and $L$. maderae. The oöcytes of pregnant females of $N$. cinerea starved during and after gestation, usually do not develop after parturition. Mating increases the percentage of females which mature their oöcytes if $N$. cinerea females that were starved during gestation are first fed for 2 or 3 days after giving birth. The combined effects of mating and nutrition on oöcyte development are in agreement with the hypothesis that mating is effective in stimulating the corpora allata only if these endocrine glands have first reached a critical level of activity.

During pregnancy, mechanical stimuli resulting from the oötheca in the uterus inhibit the corpora allata and consequently the oöcytes remain undeveloped for almost the entire $(N$. cinerea) or entire (P. surinamensis) gestation periods.

\section{References Cited}

ENGELmanN, F.

1957a. Die Steuerung der Ovarfunktion bei der ovoviviparen Schabe Leucophaea maderae (Fabr.). J. Ins. Physiol. 1: 257-278.

1957b. Bau und Funktion des weiblichen Geschlechtsapparates bei der ovoviviparen Schabe Leucophaea maderae (Fabr.) und einige Beobachtungen über die Entwicklung. Biol. Zentr. 76: 722-740.

1959. The control of reproduction in Diploptera punctata (Blattaria). Biol. Bull., Woods Hole 116, 406-419.

1960a. Mechanisms controlling reproduction in two viviparous cockroaches (Blattaria). Ann. N. Y. Acad. Sci. 89: 516-536.

1960b. Hormonal control of mating behavior in an insect. Experientia 16: 69-70.

1964. Inhibition of egg maturation in a pregnant viviparous cockroach. Nature, London, 202: 724-725.

von Harnack, M. and B. Scharrer

1956. A study of the corpora allata of gonadectomized Leucophaea maderae (Blattaria). Anat. Rec. 125, 558. Abstract.

Rотн, L. M.

1962. Hypersexual activity induced in females of the cockroach Nauphoeta cinerea. Science 138: 1267-1269.

-1964. Control of reproduction in female cockroaches with special emphasis on Nauphoeta cinerea. I. First preoviposition period. J. Ins. Physiol. 10: 915-945.

Roth, L. M. aNd R. H. Barth

1964. The control of sexual receptivity in female cockroaches. J. Ins. Physiol. 10: 965-975.

RoTh, L. M. AND W. HAHN

1964. Size of new-born larvae of cockroaches incubating eggs internally. J. Ins. Physiol. 10 : 65-72. 
Roth, L. M. AND B. STAY

1959. Control of oöcyte development in cockroaches. Science 130:271272.

1961. Oöcyte development in Diploptera punctata (Eschscholtz) (Blattaria). J. Ins. Physiol. 7: 186-202.

1962a. Oöcyte development in Blattella germanica (Linn.) and Blattella vaga Hebard (Blattaria). Ann. ent. Soc. Amer. 55: 633642.

1962b. A comparative study of oöcyte development in false ovoviviparous cockroaches. Psyche, Camb. Mass. 69: 165-208.

Roth, L. M. AND E. R. Willis

1961. A study of bisexual and parthenogenetic strains of Pycnoscelus surinamensis (Blattaria: Epilamprinae). Ann. ent. Soc. Amer. 54: $12-25$.

SCHARRER, B.

1946. The relationship between corpora allata and reproductive organs in adult Leucophaea maderae (Orthoptera). Endocrinology, $38: 46-55$.

Stay, B. And L. M. Roth

1958. The reproductive behavior of Diploptera punctata (Blattaria: Diplopteridae). Proc. 10th int. Congr. Ent. 2: 547-552 (1956). DE WILDE, T.

1961. Extrinsic control of endocrine functions in insects. Bull. Res. Counc. Israel 10B, 36-52.

Willis, E. R., G. R. Riser, and L. M. ROTH

1958. Observations on reproduction and development in cockroaches. Ann. ent. Soc. Amer. 51: 53-69. 

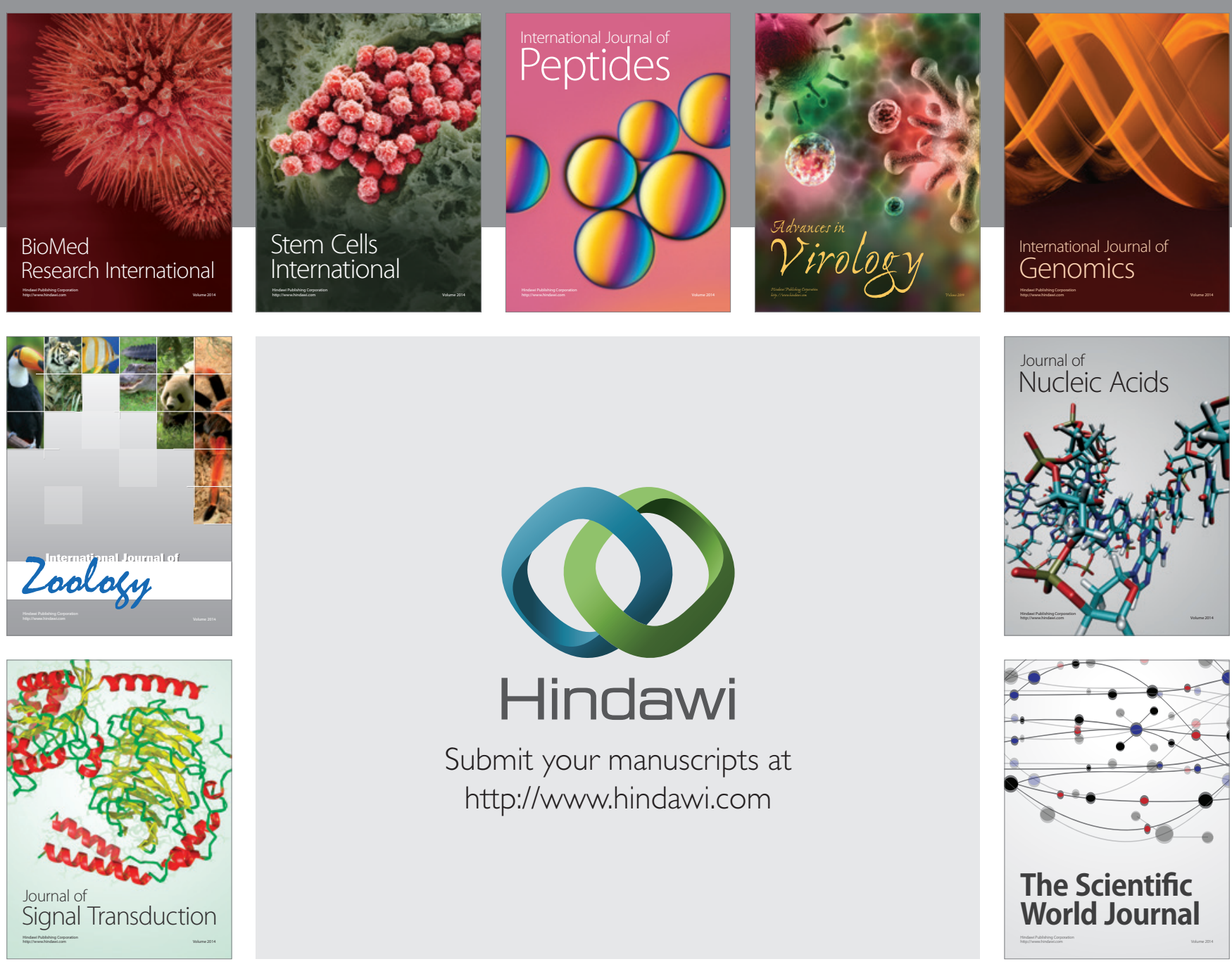

Submit your manuscripts at

http://www.hindawi.com
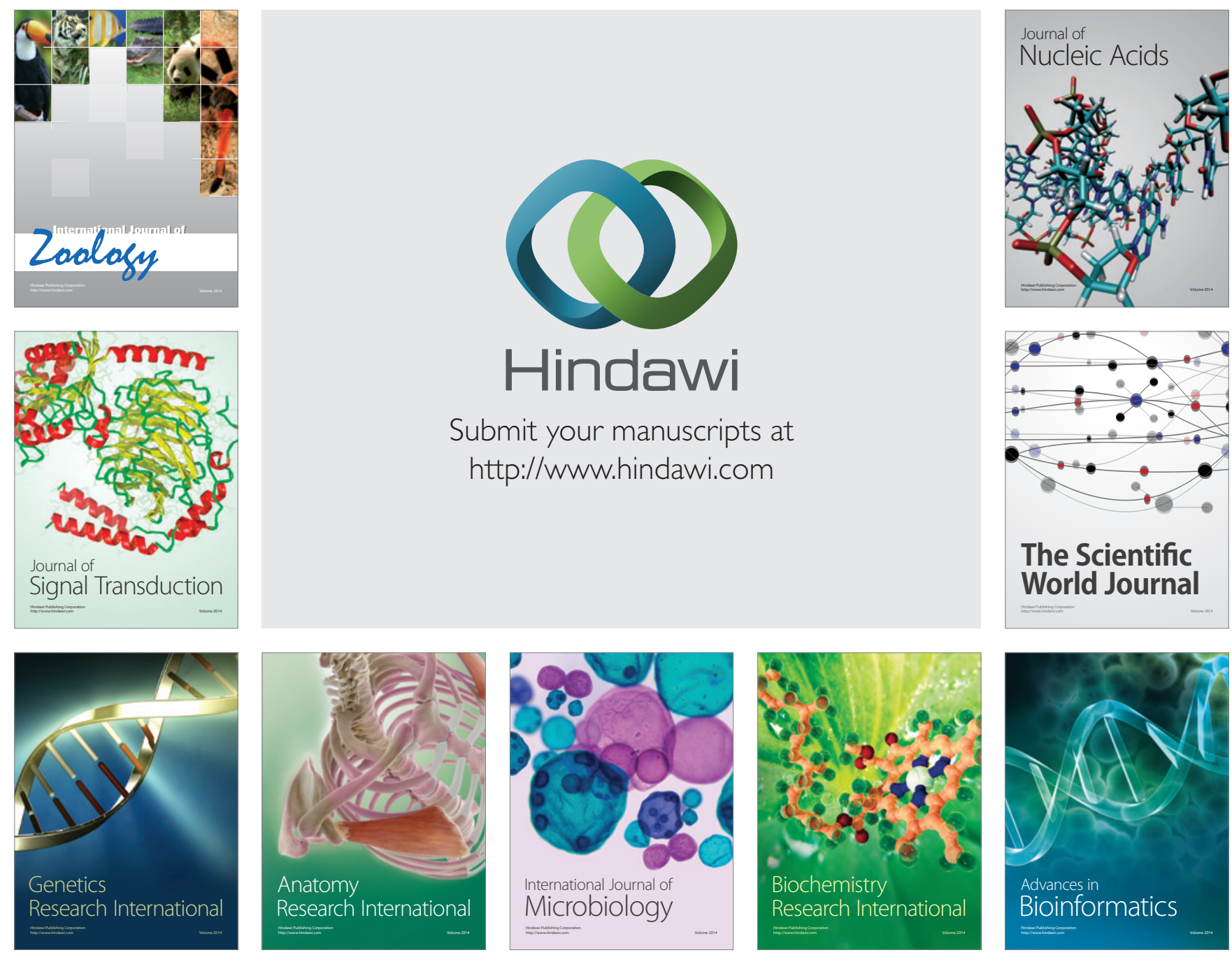

The Scientific World Journal
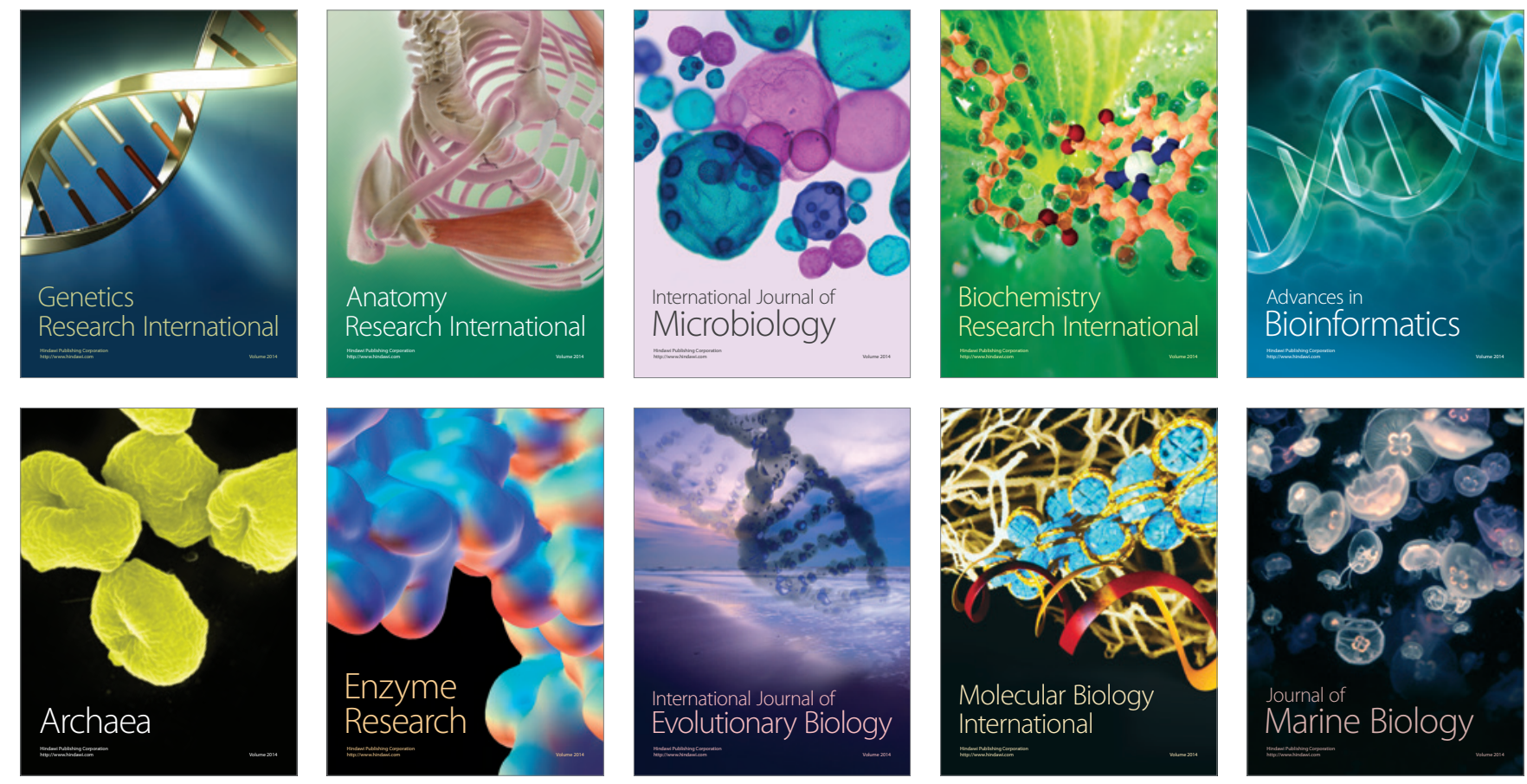